\title{
Comparative study of the counterflow forced ignition of the butanol isomers at atmospheric and elevated pressures
}

\author{
Kyle B. Brady ${ }^{\mathrm{a}}$, Xin Hui ${ }^{\dagger a, b}$, Chih-Jen Sung ${ }^{\mathrm{a}}$ \\ ${ }^{a}$ Department of Mechanical Engineering \\ University of Connecticut \\ Storrs, CT 06269, U.S.A. \\ ${ }^{b}$ National Key Laboratory of Science and Technology on Aero-Engine Aero-Thermodynamics \\ School of Energy and Power Engineering \\ Beihang University \\ Beijing, 100191, P.R. China
}

\author{
${ }^{\dagger}$ Corresponding Author: \\ Xin Hui \\ School of Energy and Power Engineering \\ Beihang University \\ 37 Xueyuan Rd. \\ Beijing, 100191, P.R. China \\ Email: huixin@buaa.edu.cn \\ Phone: (0086)-10-82339465
}

Submitted for publication in Combustion and Flame

Revised: August 25, 2015

Manuscript Reference Number: CNF-D-15-00395 


\title{
Comparative study of the counterflow forced ignition of the butanol isomers at atmospheric and elevated pressures
}

Kyle B. Brady, Xin Hui, Chih-Jen Sung

\begin{abstract}
In support of the development of robust combustion models, the present study describes experimental and computational results on the non-premixed counterflow ignition of all four butanol isomers against heated air for pressures of 1-4 atm, pressure-weighted strain rates of 200-400 s ${ }^{-1}$, and fuel molar fractions in nitrogen-diluted mixtures of 0.05-0.25. Comparison of the parametric effects of varied pressure, strain rate, and fuel loading amongst the isomers facilitates a comprehensive evaluation of the effect of varied structural isomerism on transportaffected ignition. The experimental results are simulated using isomer-specific skeletal mechanisms developed from two comprehensive butanol models available in the literature, and are used to validate and assess the performance of these models. Comparison of the experimental and computational results reveal that while both models largely capture the trends in ignition temperature as functions of pressure-weighted strain rate, fuel loading, and pressure, for all isomers both models over-predict the experimental data to an appreciable extent. In addition, neither model captures the experimentally-observed ignition temperature rankings, with both models predicting a large spread amongst $n$-/iso-/sec-butanol which does not appear in the experimental results. Sensitivity and path analyses reveal that the butene isomers play a significant role in determining the ignition temperatures of the butanol isomers in both models, with the relative branching ratios likely accounting for the ignition temperature rankings observed using each model. It is observed that the reactivity of the butene isomers varies appreciably between the two butanol models, which may account for some of the variability in predictions between the two models. Furthermore, effects of transport properties and their uncertainties on ignition temperature predictions are discussed.
\end{abstract}

Keywords: Counterflow, Ignition, Butanol isomers, Non-premixed, Skeletal mechanism 


\section{Introduction}

Despite recent advances in electric vehicle technologies, their limited range, long recharge cycles, and limited at-large charging options have constrained their consumer appeal [1]. Moreover, while significant advances in terms of energy density over current lithium battery technology are conceivable, attaining such performance will require major technological breakthroughs in terms of electrode/electrolyte materials and chemistry [2]. Alternative technologies such as fuel cell vehicles can potentially address both range and recharge/refuel time issues; however such vehicles have largely been based upon hydrogen fuel cells, which would require an entirely new, world-wide fuel distribution infrastructure to be developed. As a result, there is a clear need for combustion-based near- and intermediate-term alternative transportation energy solutions that address the pressing issues of improved efficiency, reduced emissions, and lowered lifecycle carbon footprint. While both novel engine designs and alternative fuels promise to provide efficiency gains and emissions improvements, their success is predicated upon a robust understanding of the coupled effects of chemical kinetics and convective-diffusive transport, and their accurate representation in predictive reactive-flow models under engine relevant conditions.

As part of a push towards renewable fuels and reduced emissions, alcohols have emerged as a leading prospect both for near-term performance and sustainability improvements, as well as for the long-term replacement of fossil fuels in novel engine concepts. Ethanol, the most successful of these to date, currently comprises up to $10 \%$ of all gasoline purchased in the United States and has facilitated the elimination or phase-out of both tetra-ethyl lead (TEL) and methyl tert-butyl ether (MTBE) as anti-knock additives. Through its long history, ethanol has received significant research attention and has been investigated in shock tube, flame, and reactor experiments (cf. [3]). However, the fermentation process by which the majority of ethanol is 
produced has been criticized for both its use of food-grade feedstocks as well as its low conversion efficiency, and second generation production from cellulosic plant waste has yet to be proven commercially viable. Partly as a result, so-called "second generation" alcohol-based alternative fuels such as butanol have recently received significant research attention. As a standalone alternative transportation fuel or as a fuel blend with gasoline, butanol offers several advantages over ethanol. Whereas ethanol is fully miscible with water, both $n$ - and iso-butanol isomers exhibit limited solubility with water and are less corrosive, opening up the possibility of more efficient distribution methods though pipelines. In addition, its higher energy density allows higher blending ratios with gasoline without engine modifications, and its lower vapor pressure would greatly reduce evaporative emissions. Aside from its potential impact as a transportation fuel, chemical kinetics of butanol is scientifically interesting as it represents the smallest alcohol exhibiting all forms of structural isomerism. As a result, by comparing the behavior of the butanol isomers in well-defined combustion configurations, the impacts of molecular structural variations on combustion chemistry can be better understood and broadly applied to the modeling of alcohol-based transportation fuels.

Due to the interest from both practical and scientific points of view, an appreciable body of fundamental research has been developed for butanol isomers in recent years. Though by no means a comprehensive review, numerous fundamental studies have been conducted using a variety of experimental systems including laminar flame speeds [4-7], flame extinction [8-10], pyrolysis [11], flame structure [6,12-15], species and temperature measurements in a flow reactor [12], jet-stirred reactors (JSR) [6,16], and ignition delays in rapid compression machines (RCM) [17-19] and shock tubes [20,21]. Several of these studies have investigated the impact of isomeric variations on global combustion properties. Veloo and Egolfopoulos [7] determined 
atmospheric pressure laminar flame speeds of the butanol isomers in the equivalence ratio range of $0.7-1.5$, finding highly similar flame propagation rates for $n$-/iso-/sec-butanol but significantly lower flame speeds for tert-butanol. Gu et al. [4] observed laminar flame speed differences between the various isomers, finding that the isomers followed a ranking of $n$-butanol > isobutanol $\approx$ sec-butanol > tert-butanol for atmospheric pressure. Stranic et al. [20] investigated ignition delay times of the butanol isomers in a shock tube at 1050-1600 K, 1.5-43 atm, and equivalence ratios of 0.5 and 1.0, finding that the butanol isomers exhibited noticeably different ignition delay times, with the relative rankings changing as a function of pressure. At $1.5 \mathrm{~atm}, n$ butanol exhibited the shortest ignition delay times, followed by iso- and sec-butanol, with tertbutanol exhibiting considerably longer ignition delays, whereas at 43 atm the rankings followed $n$-butanol $\approx i$ iso-butanol $<$ sec-butanol < tert-butanol. In an RCM configuration Weber and Sung [17] found quite different ignition delay trends for stoichiometric mixtures at 715-910 K and 15 and 30 bar pressures. At both pressure conditions $n$-butanol exhibited significantly faster ignition delay times than other isomers, additionally finding that the ignition delay ranking followed $n$ butanol < iso-butanol $\approx$ sec-butanol < tert-butanol at 15 bar, but $n$-butanol < tert-butanol < secbutanol < iso-butanol at 30 bar. In addition to global combustion properties, the effect of structural isomerism on intermediate species production has been explored by several studies. McEnally et al. [15] conducted speciation studies on the butanol isomers in a doped methane coflow flame at atmospheric pressure, and concluded that the dominant decomposition process was unimolecular decomposition rather than $\mathrm{H}$-abstraction. Oßwald et al. [14] conducted a molecular beam mass spectrometry (MBMS) study of the butanol isomers in a fuel-rich low-pressure laminar premixed flame, noting significant differences amongst the butanol isomers in terms of 
the intermediate species pool. In particular, large disparities were observed for butene, enol, and aldehyde species in [14].

From these and similar works, several detailed combustion models have recently been compiled and developed that comprehensively describe the chemical kinetics of butanol isomers. The model of Frassoldati et al. [22] - an update of the mechanism of Grana et al. [13] - includes all four isomers and has been validated against pyrolysis, shock tube ignition delay time, and premixed and non-premixed flame structure data. The model of Merchant et al. [23] - including all four isomers, and based upon the comprehensive model of Van Geem et al. [24] - has been validated against pyrolysis, laminar flame speed, low-pressure premixed flame structure, and shock tube ignition delay data. Additionally, the comprehensive model of Sarathy et al. [25] has been validated against laminar flame speeds, low-pressure premixed flame structures, RCM and shock tube ignition delays, and JSR species profiles.

Despite the research attention that butanol isomers have garnered, there is relatively little data exploring limit phenomena in convective/diffusive environments for these fuels. In fact, to the authors' knowledge, the only available forced ignition data came from the stagnation-pool study of Liu et al. [26] for $n$ - and iso-butanol, while flame extinction data were limited to the $n$ butanol studies of Veloo et al. [10] and Hashimoto et al. [9], and the n-, iso-, and sec-butanol study of Mitsingas and Kyritsis [8]. Ignition and extinction data in convective/diffusive systems are relevant to the operation of practical combustion devices, and can also offer a highlysensitive experimental platform for the validation of both chemical kinetic and transport models. As such, the present work compares the impact of ambient pressure, strain rate, and fuel loading on the counterflow ignition temperatures of all four butanol isomers in order to understand the isomeric structural effects on diffusive ignition. The experimental results are further simulated 
using isomer-specific skeletal mechanisms derived from comprehensive butanol models available in the literature. A comparison of experimental and simulated results is then used to validate and assess the performance of these literature butanol models.

\section{Experimental and computational descriptions}

\subsection{Experimental apparatus}

The details of the non-premixed counterflow ignition apparatus, including a detailed experimental characterization, have been previously described by the authors [27]. Briefly, the counterflow burner consists of a quartz straight-tube upper section directing heated air downward against a nitrogen-diluted fuel stream emanating from a stainless steel lower section. The air and fuel streams are surrounded by concentric nitrogen co-flow to isolate the test section from the ambient atmosphere and improve the quality of the resulting stagnation-point flow field. The air and fuel tubes have inner diameters of $D=19 \mathrm{~mm}$ and the co-flow tubes have $28 \mathrm{~mm}$ inner diameters. The air and fuel streams are separated by $L=20 \mathrm{~mm}$, resulting in an $L / D$ ratio for all experimental conditions of 1.05. Heating on the air side is accomplished using an internal helical $\mathrm{SiC}$ heater, capable of heating the airflow to $1250-1300 \mathrm{~K}$ at the tube exit depending on operating conditions, and an external heater that is used to reduce heat loss. The ignition temperature, measured as the air-side centerline boundary temperature, is determined from a $\mathrm{K}$ type bare wire thermocouple with proper radiation correction. The location of the ignition event is monitored using a Vision Research Phantom v710 high-speed camera acquiring visible-light images at a frame rate of $3000 \mathrm{~Hz}$. This frame rate is sufficient to capture the onset of ignition and facilitates determining its precise location within the test section to ensure consistency amongst data sets as well as ensure quasi-one-dimensional ignition behavior. For all the experimental data reported herein, the onset of ignition was observed to take place near the 
middle of the test section and then propagate radially in a fairly one-dimensional manner. The thermocouple design, details of the radiation correction, and discussion of the importance of monitoring ignition location have been described previously [27].

Flow control is accomplished through the use of sonic nozzles for all gases. The air stream is synthesized by a $21 \% / 79 \% \mathrm{O}_{2} / \mathrm{N}_{2}$ mixture by mole, while the nitrogen-diluted fuel stream varies between $5-25 \%$ fuel by mole. The flow rate of liquid fuel is controlled using a precision Teledyne Isco 1000D high-pressure syringe pump, with fuel vaporization accomplished through a heated spray system. The fuel vaporization system and the subsequent fuel lines are heated to surface temperatures just above the boiling point of the isomer in question to prevent surface condensation - for the current study, $\sim 140{ }^{\circ} \mathrm{C}$. For all conditions tested here, the mixture temperature at the fuel boundary is maintained at $\sim 380 \mathrm{~K}$. To ensure proper vaporization, the partial pressure of the fuel is maintained well below the corresponding saturation vapor pressure for a given butanol isomer, calculated using the correlation from Yaw's Chemical Handbook [28] at the temperature/pressure conditions within the fuel line. Furthermore, the fuel partial pressure never exceeds $50 \%$ of the calculated saturation vapor pressure for all experimental conditions in an effort to ensure complete vaporization. It is worth noting that the concentration validation has been conducted previously [27] using $n$-butanol as a model fuel. This isomer represents a "worst-case" in terms of condensation as it exhibits the lowest vapor pressures. Since no condensation was observed for the $n$-butanol concentration validation, the fuel line settings can be presumed adequate for all butanol isomers.

As has been thoroughly described in previous work [27], both systematic and random uncertainties are relevant to the analysis of the present experimental results. Systematic uncertainty results from defects in a parameter model (e.g., Nusselt number for thermocouple 
radiation correction) or measuring equipment (e.g., pressure gauges) which cause system-wide deviations from true behavior. Such uncertainty results in reproducible inaccuracies that tend to impact the entire data set in a largely equivalent manner. Random error represents statistical fluctuations in measured data based upon the precision of the measurement device, and their impact can be minimized through averaging of multiple observations. These definitions are important to the present analysis because, while the total uncertainty (including both systematic and random errors) is relevant for the comparison of experimental and numerical ignition temperatures, only the random error is applicable when comparing amongst the experimental results since all data should be equally affected by systematic errors. As a result, comparisons amongst the experimental isomer ignition temperature data should be compared using the random error $( \pm 5 \mathrm{~K})$, while comparisons between experimental and numerical data are best compared using the total estimated uncertainty (systematic plus random), which ranges from 20 $\mathrm{K}$ for the lowest ignition temperatures to $35 \mathrm{~K}$ for the highest [27].

\subsection{Experimental procedure}

In the present experiments, the oxidizer boundary temperature at the onset of ignition is denoted as the ignition temperature $\left(\mathrm{T}_{\mathrm{ig}}\right)$. The procedure for acquiring this temperature is as follows: 1$)$ The internal, external, and flow system heaters are brought up to a steady-state temperature close to the ignition state, the desired gaseous mass flow rates (excepting any fuel) for a given strain rate condition are set on the flow system, and the chamber is pressurized to the desired set point. 2) Fuel is introduced through the flow system and allowed to come to steady state. 3) The highspeed camera begins acquiring data, and the air temperature is gradually raised by increasing power to the internal heater until a flame ignites. 4) The fuel supply is shut off to extinguish the flame. 5) The thermocouple solenoid is activated, rotating the thermocouple bead to the center of 
the air duct and the air temperature, along with the fuel-side gas temperature, is recorded. 6) The images acquired from the high-speed camera are checked to verify that ignition occurs at or near the longitudinal axis, and that it occurs near the middle of the test section, $\pm 2 \mathrm{~mm}$. If ignition occurs too far towards the fuel or oxidizer exits, the flow rates are adjusted to move the stagnation plane in the appropriate direction while maintaining a constant global strain rate. In addition, if ignition occurs at a temperature more than $10 \mathrm{~K}$ away from the estimated temperature used to compute flow rates for a given global strain rate, the flow rates are updated and Steps 26 are repeated. Steps 2-6 are repeated a minimum of three times once the proper flow settings have been achieved to ensure a consistent value for $\mathrm{T}_{\mathrm{ig}}$.

Here, the global strain rate $(K)$ is defined based on the relation of Seshadri and Williams [29]: $K=\frac{2 V_{O}}{L}\left(1+\frac{V_{F} \sqrt{\rho_{F}}}{V_{O} \sqrt{\rho_{O}}}\right)$, where $V$ is the bulk velocity at the boundary, $L$ is the separation distance, $\rho$ is the density, and the subscripts $F$ and $O$ represent the fuel and air boundaries, respectively. The adequacy of this global strain rate definition to account for the effects of varying density due to the temperature gradients inherent to counterflow ignition has been demonstrated in [27]. Following the work of Fotache et al. [30], the pressure-weighted strain rate $\left(k^{\prime}\right)$, defined as $k^{\prime}=\frac{P_{C}}{P_{\text {ref }}} K$, is used to isolate the chemical effect of pressure variations by keeping the spatial scalar structure (temperature and concentration profiles) approximately constant. In the definition of $k^{\prime}, P_{C}$ is the chamber pressure and $P_{r e f}$ is a reference pressure, taken throughout this work as 1 atm.

\subsection{Computational specifications}

The ignition state is modeled using an in-house counterflow non-premixed ignition code based on the potential-flow formulation of Smooke et al. [31] and identical to that used previously [27]. As in the work of Kreutz et al. [32], the ignition temperature corresponds to the turning point of 
the lower-branch ignition response curve with respect to air boundary temperature, while the current navigation of the ignition turning point is achieved using the two-point flame-controlling continuation method developed by Nishioka et al. [33]. In this study, the $\mathrm{H}$ radical is chosen as the controlled species due to its crucial role in governing ignition, although other key radicals are equally applicable [33]. For a given strain rate, the use of the two-point $\mathrm{H}$-controlling continuation requires boundary conditions of the mixture compositions at both fuel and oxidizer boundaries and the fuel boundary temperature ( $380 \mathrm{~K}$ in the current work), along with the $\mathrm{H}$ concentration values at two different locations as internal boundary conditions [33]. As such, the mass fluxes at the fuel and oxidizer boundaries are solved as edge values, while the air boundary temperature becomes the system response [33]. By varying the $\mathrm{H}$ concentration values at the two selected locations, continuous mapping of the ignition response curve is then obtained. It is also worth noting that because of the convective/diffusive process involved in the counterflow nonpremixed configuration and the Arrhenius dependence of reaction rates favoring a higher temperature environment, the ignition kernel is located on the air side of the stagnation surface and its local stoichiometry is always very lean. This has been demonstrated in Fotache et al. $[34,35]$ using $\mathrm{C}_{1}-\mathrm{C}_{4}$ alkanes, for cases with fuel concentrations at the boundary ranging between $6 \%$ and $100 \%$. A similar situation is also observed in the present study of butanol isomers.

Similar to the procedure discussed in previous work [27], skeletal mechanisms specific to each isomer are created using the Directed Relation Graph with Error Propagation (DRGEP) implementation of the Mechanism Automatic Reduction Software (MARS) package of Niemeyer and co-authors [36-39]. Each skeletal mechanism is reduced using constant-volume ignition delays for equivalence ratios of $0.5-2$, pressures of $1-40$ atm, and temperatures of $1000-1800 \mathrm{~K}$, using the fuel, $\mathrm{N}_{2}$, and $\mathrm{O}_{2}$ as target species. In addition, the reduction procedure utilizes perfectly 
stirred reactor (PSR) extinction profiles for inlet temperatures of 400 and $500 \mathrm{~K}$, covering the same range of pressure and equivalence ratio as the autoignition results. For both ignition delay and PSR targets, the maximum error tolerance during the reduction process is set at $10 \%$. As mentioned in the introduction, a number of detailed kinetic mechanisms for butanol isomers have been developed in recent years, including the models of Frassoldati et al. [22], Merchant et al. [23], and Sarathy et al. [25], each validated for all four butanol isomers. Unfortunately, the inclusion of non-integer stoichiometric coefficients in the Frassoldati model makes it incompatible with both the current Chemkin-based ignition code and the MARS package, as well as running exceedingly slowly in CHEMKIN-PRO [40]. Hence, only the Sarathy and Merchant models are included and compared in the present study. The resulting isomer-specific skeletal mechanisms are referred to hereafter as SN, SI, SS, and ST (referring to the $n-$, iso-, sec-, and tert-butanol skeletal mechanisms derived from the Sarathy detailed model), and MN, MS, and MT (referring to the $n$-, sec-, and tert-butanol skeletal mechanisms derived from the Merchant detailed model). Due to some issues arising from iso-butanol-relevant reactions in the Merchant model, which are detailed in Section 2.4.1, the skeletal reduction cannot be conducted for isobutanol, and hence "MI" is lacking here.

Validation of the skeletal mechanisms for each of the isomers is shown in Fig. 1, by plotting the computed peak mole fraction of hydrogen radical as a function of air boundary temperature $\left(T_{O}\right)$ for the cases with fuel mole fraction of $X_{\mathrm{f}}=0.15$ in the nitrogen-diluted fuel stream. For all isomers, the skeletal Sarathy mechanisms perform nearly identically to the detailed model at both 1 and $5 \mathrm{~atm}$, with a maximum deviation of $\sim 5 \mathrm{~K}$ shown by the ST mechanism at $5 \mathrm{~atm}$ where the skeletal mechanism under-predicts the detailed model. The skeletal Merchant mechanisms also perform quite well, with a maximum deviation of $<1 \%$ for the $\mathrm{MN}$ mechanism at $5 \mathrm{~atm}$, where 

detailed model by $<5 \mathrm{~K}$, while the MT mechanism exhibits turning points essentially identical to those of the detailed model. In general, the Merchant model predicts higher ignition temperatures than the Sarathy model. Additional validation of the resulting skeletal mechanisms includes the targets of ignition delay times, PSR response curves, and laminar flame speeds over a wide range of conditions. Some comparative results for $n$-butanol can be found in the Supplementary Material of [27].

Table 1 summarizes the size of each mechanism used in this study in terms of number of species and reactions, including both the detailed and skeletal mechanisms. All the skeletal mechanisms generated in this study are included in the Supplementary Material.

\subsection{Modifications to combustion models}

In the course of investigating the butanol isomers numerically, several important issues with the Merchant and Sarathy models have become apparent, and have necessitated modification of the mechanisms and the exclusion of certain data. Due to the significant impact of these changes and their implications on future modeling studies, these modifications are detailed in the following sections and are incorporated into the respective skeletal mechanisms.

\subsubsection{Merchant model}

In the course of mechanism reduction, it was discovered that the Merchant model contains several reactions in the PLOG format that contain negative pre-exponential factors. The PLOG format provides the flexibility to describe reaction rates in different pressure ranges by different Arrhenius coefficient sets. For pressures intermediate between two reaction rate descriptions, a linear interpolation for $\ln (k)$ is used to obtain the reaction rate:

$$
\ln k=\ln k_{i}+\left(\ln k_{i+1}-\ln k_{i}\right)\left[\frac{\ln P-\ln P_{i}}{\ln P_{i+1}-\ln P_{i}}\right], \quad \text { Eqn. } 1
$$


where $k$ is the interpolated reaction rate, $k_{i}$ and $k_{i+1}$ are the reaction rates at pressures bracketing the pressure for which $k$ is desired, and $P$ is the pressure, with the subscripts following an identical nomenclature. Since the logarithm of a negative number is undefined, the PLOG interpolation cannot be evaluated for negative values of $k_{i}{ }^{\prime} s$. Such a situation arises for the $i s o$ butanol decomposition reaction, producing methyl radical and 2-hydroxypropyl, where the formatting of this reaction as a "declared duplicate" forces interpolation using a negative reaction rate. As a result, both the ignition code and the mechanism reduction code fail. It is worth noting that when the same mechanism is used in CHEMKIN-PRO [40], the calculation neither fails nor displays any warning messages. Given the nature of the interpolation, it is unclear what allows CHEMKIN-PRO calculations to proceed.

For the purposes of the present study, the above-mentioned iso-butanol decomposition reaction is problematic in that its reaction rate cannot be evaluated. In order to facilitate as broad a mechanism comparison as possible, this reaction is manually removed so that skeletal mechanisms for $n$-, sec-, and tert-butanol can be obtained and used in the ignition code. This methodology is deemed valid for these isomers given that the reverse of this removed reaction should at most represent a minor recombination pathway in these cases. However, given that this iso-butanol decomposition reaction defines one possible pathway for iso-butanol destruction, it cannot be removed from the mechanism a priori without potentially significant impacts to the fidelity of an iso-butanol skeletal mechanism. As a result, no computational data for iso-butanol from the Merchant model is shown in this work.

\subsubsection{Sarathy model}

In the course of evaluating the impact of transport parameters on the ignition temperature of the butanol isomers, it was discovered that, while the Lennard-Jones parameters for $n$-butanol were 
quite similar between all three models [22,23,25], the parameters for iso-, sec-, and tert-butanol within the Sarathy model differed significantly from the parameters used in both the Frassoldati and Merchant models. While nitrogen-fuel binary diffusion coefficients for $n$-butanol differed between the Merchant and Sarathy models by only 5\%, the computed diffusion coefficients for the other three isomers were as much as $125 \%$ larger in the Sarathy model. In fact, the stated values for collision diameter were almost half that of similar $\mathrm{C}_{4}$ species, and even smaller than those of the oxygen and hydroxyl radicals. Following the procedures laid out in Sarathy et al. $[6,25]$ for the estimation of transport parameters, values more similar to those found in the Frassoldati and Merchant models were obtained, suggesting that these parameters included in the transport database of Sarathy et al. [25] were questionable. It is worth noting that different transport parameters for the butanol isomers were included in a recent hierarchical $\mathrm{C}_{1}-\mathrm{C}_{5}$ alcohol model developed by Sarathy et al. [41]. These values result in closer agreement with the Merchant transport model ( $15 \%$ larger nitrogen-fuel diffusion coefficients). However, this change was not described by Sarathy et al. [41], and the new transport parameters do not appear to coincide with the stable-species transport parameter correlation methodology stated in [25]. Thus, it is unclear how these parameters were derived in [41].

As will be shown in detail in Section 3.2, the effect of such large discrepancies in diffusion coefficients is significant. As a result, the transport parameters for the three butanol isomers - as well as all related $\mathrm{C}_{4}$ species that use identical parameters to the respective parent fuel - are modified to the corresponding parameters used in the Merchant model and the resulting transport database is used to compute all numerical results presented for the Sarathy model. Since the transport properties are otherwise similar, this change not only modifies the transport parameters 
to more realistic values, but also facilitates a more direct comparison of the underlying chemistry of the two models.

\section{Ignition results and discussion}

\subsection{Experimental results}

Figure 2 demonstrates the effect of strain rate on the ignition temperature of the four butanol isomers at 1 and 3 atm for $\mathrm{X}_{\mathrm{f}}=0.15$. Only a single data point for tert-butanol is included at 1 atm due to the difficulty in igniting this fuel under atmospheric conditions. All isomers respond similarly to varied strain rate within the range of $k^{\prime}=200-400 \mathrm{~s}^{-1}$, with the differences between the isomers narrowing slightly as strain rate increases. However, two interesting features with regards to isomer ranking are apparent. First, tert-butanol exhibits significantly higher ignition temperatures relative to the other three isomers. This ignition temperature difference amounts to $43-57 \mathrm{~K}$ at $1 \mathrm{~atm}$, and $64-83 \mathrm{~K}$ at 3 atm. Second, the relationship between iso- and sec-butanol reverses between 1 and 3 atm. While iso-butanol exhibits the highest ignition temperature amongst the $n / i s o / s e c$-butanol group at 1 atm, sec-butanol occupies this position at 3 atm. Similar behaviors are observed when comparing the isomers in terms of the effect of fuel loading. As shown in Fig. 3 for $k^{\prime}=350 \mathrm{~s}^{-1}$, while all isomers exhibit highly similar behavior as a function of fuel loading, the relative ranking between iso- and sec-butanol again changes between 1 and 3 atm and is consistent across the fuel loading range investigated. It is worth noting that while the differences amongst the n/iso/sec-butanol group are relatively small (on the order of 5-20 K), in general the noteworthy trends involve ignition temperature differences in excess of the maximum random error estimated from repeated measurements at the same operating conditions $( \pm 5 \mathrm{~K})$. In addition, the aforementioned trends are consistent across a wide range of strain rate and fuel 

and therefore merit further investigation.

Figure 4 provides a clearer demonstration of the iso/sec-butanol ranking switch by plotting ignition temperature as a function of pressure at $k^{\prime}=350 \mathrm{~s}^{-1}$ and $\mathrm{X}_{\mathrm{f}}=0.15$. A clear crossover point for these isomers exists between 2 and 2.5 atm; below this pressure sec-butanol is the more reactive one of the pair, while above this pressure iso-butanol becomes more reactive. Throughout the pressure range, tert-butanol exhibits significantly higher ignition temperatures than the other three isomers. It is worth noting that similar "crossover" behavior has been observed in homogenous experiments involving similar temperature ranges. The shock-tube study of Stranic et al. [20] found that at $1.5 \mathrm{~atm}$, the ignition delay times of iso- and sec-butanol were quite similar, while at higher pressures sec-butanol exhibited noticeably longer ignition delays than iso-butanol. In addition, in line with the results of the present study, tert-butanol manifested significantly longer ignition delays under all pressure conditions investigated.

\subsection{Effect of transport model uncertainties in the Sarathy mechanism}

As discussed in Section 2.4.2, the original transport data contained in the mechanism of Sarathy et al. [25] has apparent discrepancies in the Lennard-Jones parameters for iso-, sec-, and tertbutanol, as compared to those of Frassoldati et al. [22] and Merchant et al. [23]. The effect of changing these parameters - for both the parent fuel molecules and related $\mathrm{C}_{4}$ intermediates using identical values to the respective parent fuel - to those used by Merchant et al. [23] is exemplified in Fig. 5 for 3 atm, $k^{\prime}=350 \mathrm{~s}^{-1}$ conditions. In addition to being shifted upwards by 55-100 K, the sensitivity of ignition temperature to fuel loading (i.e. rate of change as a function of fuel loading) is also increased. Comparing the original and modified transport model results, the difference between predicted ignition temperatures at $\mathrm{X}_{\mathrm{f}}=0.05$ and 0.25 is $\sim 60-70 \mathrm{~K}$ for all 
three isomers using the original parameters, however using the modified model this difference increases to $100-110 \mathrm{~K}$.

Comparing the numerical results to the accompanying experimental results in Fig. 5, it is clear that this modification results in a greater disagreement with experimental data than the original model, with the difference between experimental and numerical data rising to between 80-120 K, depending on the isomer and operating conditions in question. While this modification could hardly be termed an "improvement" in terms of fidelity to experimental results, it does serve to illustrate two important points. First, it is imperative to include nonpremixed validation data during combustion model development to provide more rigorous validation of the transport model. The larger sensitivities of non-premixed systems to transport properties can help to improve the performance of the complete combustion model in transportaffected environments, a designation encompassing most practical combustion devices. Second and most relevantly for the present discussion - while transport parameters exhibit significantly larger sensitivities relative to individual reactions (to be discussed in due course), the fuel diffusion coefficients of the original model would have to be increased by an excessively large amount to close the gap between the numerical and experimental data. Since the resulting transport parameters would then be entirely unreasonable - as outlined in Section 2.4.2 alternative factors must be considered to account for the differences. This observation proves valuable in the evaluation of the Sarathy and Merchant models, as modification of the fuel transport parameters - within reasonable bounds - cannot account for the disparity between numerical and experimental results, and thus the source of the remaining disparities must lie within the chemical kinetic mechanism. 


\subsection{Numerical results from the Sarathy model}

While the accompanying numerical results to Figs. 2 and 3 have been computed, the trends in terms of strain rate and fuel loading are highly similar amongst the various isomers within a given mechanism set, and largely capture the experimentally-observed trends. As a result, the following description and analysis will focus on the effect of varied pressure. Figure 6 shows a comparison between the experimentally obtained ignition temperatures and numerical results computed using the SN, SI, SS, and ST mechanisms for $k^{\prime}=350 \mathrm{~s}^{-1}, \mathrm{X}_{\mathrm{f}}=0.15$, and $\mathrm{P}=1-4 \mathrm{~atm}$. Several interesting observations can be made from Fig. 6. First, the numerical results for all isomers over-predict the experimental results by an appreciable extent, ranging from 70 to $140 \mathrm{~K}$ $(6-10 \%)$. While such a deviation could be considered relatively small on a percentage basis, it should be noted that the gap between numerical and experimental results is of similar magnitude to the difference between 1 and 4 atm experimental ignition temperatures. As such, the difference between numerical and experimental results should be considered significant within the context of the experimental data. Second, while the experimental ignition temperature trends for n/iso/sec-butanol as a function of pressure are largely well-captured by its accompanying numerical results, for tert-butanol the difference is more dramatic. At 1 atm the difference stands at $140 \mathrm{~K}$, however at 4 atm the gap shrinks to just $70 \mathrm{~K}$. Interestingly, the numerical results for the butanol isomers exhibit one of two behavior sets corresponding to the isomer types; the positional isomers ( $n$ - and sec-butanol) exhibit a highly similar rate of change as a function of pressure, while the branched chain isomers (iso- and tert-butanol) also exhibit remarkable similarity but with a slightly greater pressure sensitivity. Third, unlike the experimental data where $n-$, iso-, and sec-butanol exhibit highly similar ignition temperatures, the results from the Sarathy model predict a noticeable offset between $n$-butanol and iso/sec-butanol. This behavior 
suggests appreciable differences in the modeled fuel breakdown chemistry, a subject that will be explored further in due course. Finally, the crossover between the iso- and sec-butanol results observed experimentally is reproduced by the numerical results, with both the crossover pressure and the difference between the two isomers at 1 and 4 atm closely matching those seen experimentally. This suggests that while overall the ignition temperatures are shifted upwards relative to the experimental data, the Sarathy model nonetheless captures some of the isomerspecific differences in terms of pressure-dependent reactions.

To begin to explore some of the above observations, a sensitivity analysis is conducted for reaction rates (by perturbing pre-exponential factors, $A_{i}{ }^{\prime} \mathrm{s}$ ) and binary diffusion coefficients (by perturbing the zeroth-order coefficients of the polynomial fits for $D_{j k}$ 's) defined as $S_{A i}=\frac{\partial \ln T_{i g}}{\partial \ln A_{i}}$ and $S_{D j k}=\frac{\partial \ln T_{i g}}{\partial \ln D_{j k}}$, respectively. Figures 7-10 demonstrate the ten largest reaction rate and transport sensitivity coefficients for all four butanol isomers, computed at the ignition turning points for 1 and 4 atm pressures, $k^{\prime}=350 \mathrm{~s}^{-1}$, and $\mathrm{X}_{\mathrm{f}}=0.15$, ranked by the sensitivity magnitude at 4 atm. Similar to the results previously discussed by the authors [27], for each isomer the sensitivity analysis of binary diffusion coefficients demonstrates significant sensitivity to the $\mathrm{N}_{2}$ butanol and $\mathrm{O}_{2}$-butanol transport rates as well as those of several important intermediates. Of particular note is the consistent importance of butene isomers $\left(1-\mathrm{C}_{4} \mathrm{H}_{8}, 2-\mathrm{C}_{4} \mathrm{H}_{8}\right.$, and $\left.i \mathrm{C}_{4} \mathrm{H}_{8}\right)$ in the transport sensitivity analysis for each of the butanol isomers. Sarathy et al. [25] attributed the lower experimental laminar flame speeds of iso- and tert-butanol relative to $n$-butanol to the predominance of iso-butene $\left(i C_{4} H_{8}\right)$, and additionally noted that the branching ratios for isomerization and beta-scission of hydroxybutyl radicals warranted improvement to better predict the formation of butene isomers. Indeed, deficiencies were noted compared to both lowpressure flame speciation and JSR experiments. As a result, the persistent appearance of butene 
isomers in the present analysis suggests that further investigation of their role in counterflow ignition merits further examination, and will be discussed in more detail in conjunction with path analyses in due course.

Examination of reaction rate sensitivity analyses in Figs. 7-10 demonstrates additional differences associated with differing isomerism. Comparing amongst the positional isomers $(n$ butanol and sec-butanol), noticeable correspondence is apparent in terms of the sensitive reaction rates, with both isomers primarily exhibiting sensitivity to $\mathrm{H}_{2} / \mathrm{C}_{1}$ chemistry. In contrast, while the branched chain isomers (iso-butanol and tert-butanol) also exhibit sensitivity to $\mathrm{H}_{2} / \mathrm{C}_{1}$ chemistry, a number of reactions involved in the early stages of fuel breakdown also appear in the sensitivity analysis. For iso-butanol, this includes the initial $\mathrm{H}$-abstraction from the $\alpha$ and $\gamma$ sites, as well as subsequent $\mathrm{H}$-abstraction and scission reactions from the $\alpha$-hydroxybutyl radical. Similarly, tert-butanol displays substantial sensitivity to fuel breakdown reactions through both iso-butene and propen-2-ol $\left(\mathrm{CH}_{2}=\mathrm{COHCH}_{3}\right)$ pathways. Interestingly, for both branched chain isomers the fuel breakdown reactions display appreciable pressure sensitivity in contrast to the positional isomers where - with the exception of hydrogen peroxide decomposition and $\mathrm{H}$ abstraction from the parent fuel via hydroperoxyl - most reactions display comparatively less pressure sensitivity. This difference may account for the different variation of ignition temperature with pressure between the positional and branched chain isomers observed in the numerical results.

Figures 11-14 show spatially-integrated path flux analyses at the ignition turning point for the butanol isomers at $k^{\prime}=350 \mathrm{~s}^{-1}, \mathrm{X}_{\mathrm{f}}=0.15$, and atmospheric pressure. In agreement with the sensitivity analysis, the butene isomers feature prominently in the initial fuel breakdown steps for all butanol isomers, albeit to differing extents. The path analysis for $n$-butanol (Fig. 11) shows 
that the majority of the 1-butene produced is through $\beta$-hydroxybutyl radical decomposition, with a minor pathway to 1-butene directly from $n$-butanol. In comparison, noticeably more butenes production is apparent in the flux maps of the other isomers. Approximately $6 \%$ of $i s o$ butanol (Fig. 12) is converted directly to iso-butene, and $\sim 80 \%$ of the $\beta$-hydroxybutyl radical is consumed through decomposition to iso-butene. The sec-butanol analysis (Fig. 13) shows significant paths to both 1-butene and 2-butene through the $\beta$-hydroxybutyl radicals, as well as minor pathways to each directly from the parent fuel. Finally, the overwhelming majority of tertbutanol consumption (Fig. 14) occurs through iso-butene, either directly from the parent fuel or via the hydroxybutyl radical. Interestingly, the ignition temperature ranking of the isomers at 1 atm based on the Sarathy model $-n$-butanol $<$ iso-butanol $<$ sec-butanol $<$ tert-butanol correlates well with the relative production of butenes by each isomer. This correspondence suggests that the butene chemistry plays a significant role in prescribing the ignition temperature trends observed amongst the butanol isomers, specifically their relative ranking in terms of ignition temperature, and may account for the disparity observed between experimental and numerical results when comparing $n$-butanol with iso-/sec-butanol. This possibility will be explored in more detail in Section 3.5.

\subsection{Numerical results from the Merchant model}

Figure 15 compares the numerical results derived from the MN, MS, and MT mechanisms to the experimentally obtained ignition temperatures for $k^{\prime}=350 \mathrm{~s}^{-1}, \mathrm{X}_{\mathrm{f}}=0.15$, and $\mathrm{P}=1-4$ atm. As mentioned in Section 2.4.2, iso-butanol results are not shown due to the inability of the MARS reduction package or the ignition code to interpret the aforementioned iso-butanol decomposition reaction in its current PLOG form. The corresponding results using the skeletal Sarathy mechanisms are also shown in Fig. 15 for comparison. Similar to the results in the previous 
section, the skeletal Merchant mechanisms universally over-predict experimental ignition temperatures - in this case by $\sim 100-190 \mathrm{~K}$. In addition, the MS mechanism predicts sec-butanol ignition temperatures offset from the $n$-butanol results predicted using the MN mechanism by 20-40 K, with the disparity rising as pressure increases. In fact, based on the skeletal Merchant mechanisms, the sec-butanol results are more similar in magnitude to those for tert-butanol, and exhibit the highest ignition temperatures for pressures above $\sim 2$ atm. This behavior runs counter to the experimental results, where tert-butanol consistently ignites at appreciably higher temperatures than the other three isomers, which ignite at largely similar temperatures for most operating conditions. Unlike the results from the skeletal Sarathy mechanisms, sec-butanol and $n$-butanol are not predicted to exhibit similar ignition temperature variation with pressure in the Merchant model, which in fact seems to capture a slight divergence in ignition temperature trend observed experimentally between the two isomers at elevated pressures.

Sensitivity analyses of the ten largest reaction rate and transport sensitivity coefficients for $n-$, sec-, and tert-butanol isomers are shown in Figs. 16-18, respectively. The results are largely similar to those obtained using the skeletal Sarathy mechanisms, with the positional isomers exhibiting sensitivity to many of the same reactions and tert-butanol showing strong sensitivity to early-stage fuel breakdown reactions. Also similar to the results of the previous section, a consistent dependence upon the transport of butene isomers is observed. However, there are some notable differences. The $n$-butanol results (Fig. 16) demonstrate sensitivity to H-abstraction from the fuel molecule via hydroperoxyl to form $\beta$-hydroxybutyl, as compared to the SN mechanism which exhibits sensitivity to abstraction at the $\alpha$-carbon. In addition, the MN mechanism is noticeably less sensitive to the chain-branching $\mathrm{H}+\mathrm{O}_{2} \leftrightarrow \mathrm{O}+\mathrm{OH}$ reaction at 1 atm relative to the $\mathrm{SN}$ mechanism. 
With regards to sec-butanol (Fig. 17), while the reaction rate sensitivity results are quite similar aside from minor differences in coefficient magnitude, the MS mechanism exhibits a greater degree of sensitivity to the transport properties of both 1-butene and 2-butene. Also of interest is the presence of propen-2-ol in the transport sensitivity analysis of Fig. 17(b). As pointed out by Sarathy et al. [25], the allylic radical of propen-2-ol exhibits resonant stabilization characteristics and thus is expected to be relatively unreactive. Since path analysis on the MS mechanism predicts that almost a quarter of propen-2-ol is consumed to form the allylic radical at both 1 and 4 atm, the relatively large negative transport sensitivity of propen-2-ol may indicate that enhanced transport results in migration of propen-2-ol to locations where alternative pathways - e.g., tautomerization to acetone - become more prevalent, thus avoiding the less reactive allylic radical pathway.

Sensitivity results for tert-butanol (Fig. 18) also display significant similarities to the ST mechanism, with iso-butene, propen-2-ol, and acetone featuring prominently in the transport sensitivity analysis, and reactions related to iso-butene comprising a significant proportion of the most sensitive reaction rates. Of note in the reaction rate sensitivity analysis shown in Fig. 18(a) is the sign change in the sensitivity coefficient for the water elimination reaction from tertbutanol: $t \mathrm{C}_{4} \mathrm{H}_{9} \mathrm{OH} \leftrightarrow i \mathrm{C}_{4} \mathrm{H}_{8}+\mathrm{H}_{2} \mathrm{O}$. While at atmospheric conditions an increase in this reaction rate tends to inhibit ignition, at 4 atm this trend reverses, suggesting a significant pressuredependent change in this important fuel breakdown reaction. This strong pressure dependence may be partially responsible for the growing disparity between the two numerical sets of tertbutanol results as pressure increases.

Furthermore, for the sensitive reactions related to $\mathrm{H}_{2} / \mathrm{C}_{1}-\mathrm{C}_{2}$ chemistry shown in Figs. 7-10 and Figs. 16-18, their reaction rates over a temperature range relevant to the present study are 
compared between the Sarathy and Merchant models. This comparison shows that the reaction rates of most of them are quite similar except that noticeable differences exist for the reactions of $\mathrm{C}_{2} \mathrm{H}_{3}+\mathrm{O}_{2} \leftrightarrow \mathrm{CH}_{2} \mathrm{CHO}+\mathrm{O}$ and $\mathrm{OH}+\mathrm{C}_{2} \mathrm{H}_{4} \leftrightarrow \mathrm{C}_{2} \mathrm{H}_{3}+\mathrm{H}_{2} \mathrm{O}$. It should be highlighted that replacing the rate coefficients for these two reactions in the Sarathy model with those from the Merchant model results in better agreement between the two models. However, a significant disparity remains, suggesting that additional differences exist in the $\mathrm{C}_{2}$ sub-mechanism between the Sarathy and Merchant models.

To investigate the isomeric differences further, path analyses at the ignition turning point for n-, sec-, and tert-butanol using the MN, MS, and MT mechanisms are shown in Fig. 19 for 1 atm, $k^{\prime}=350 \mathrm{~s}^{-1}$, and $\mathrm{X}_{\mathrm{f}}=0.15$. As was the case in the previous section, the butene isomers figure prominently in the path analysis for each isomer, with the molar flux proceeding through butene pathways roughly correlating to the trend in ignition temperature (at 1 atm), namely $n$-butanol < sec-butanol < tert-butanol. However, several noteworthy differences are apparent in the path analyses of sec-butanol (Fig. 19(b)) and tert-butanol (Fig. 19(c)). First, while the MS and SS mechanisms predict a similar flux of parent fuel to the $\alpha$-hydroxybutyl radical $(27 \%$ versus $29.3 \%$, respectively) as well as the same major products (propen-2-ol and methyl radical or 2butanone), the branching ratios from the $\alpha$-hydroxybutyl radical are nearly reversed. Whereas the MS mechanism predicts $39.4 \%$ of $\alpha$-hydroxybutyl is converted to propen-2-ol and $60 \%$ to 2 butanone, the SS mechanism predicts $74.8 \%$ proceeds to propen-2-ol while only $23.1 \%$ is converted to 2-butanone. It is worth noting that unlike the MS mechanism, the SS mechanism does not contain a pathway to propen-2-ol's allylic radical. Second, the molar flux through 1butene and 2-butene pathways is significantly larger in the MS mechanism. Nearly $55 \%$ of the parent fuel in the MS mechanism is consumed through butene-related pathways - either directly 
from sec-butanol via water elimination or indirectly via the $\beta$-hydroxybutyl radicals - as compared to $12 \%$ in the SS mechanism. As other pathways are largely similar between the two mechanisms, the large difference in the level of butene involvement is likely responsible for the differences observed between the sec-butanol ignition temperatures for the MS and SS mechanisms.

Comparing the MT mechanism path analysis results (Fig. 19(c)) to those of the ST mechanism (Fig. 14), it can be seen that the MT mechanism predicts somewhat more water elimination to directly form iso-butene while forming relatively less hydroxybutyl and almost no hydroxypropyl radicals. The MT mechanism also predicts less conversion of hydroxybutyl to iso-butene, instead favoring more production of propen-2-ol. The resulting total molar flux through iso-butene pathways is fairly similar between the two mechanisms ( 62\% in the MT mechanism compared to $\sim 69 \%$ in the ST Mechanism), which likely accounts for the quite similar predictions in terms of ignition temperatures at 1 atm. However, as pressure increases the predicted ignition temperatures begin to diverge, with the MT mechanism predicting tert-butanol ignition temperature $\sim 20 \mathrm{~K}$ higher than the ST mechanism at $4 \mathrm{~atm}$. This difference is attributed to a significant increase in the importance of the ROOH pathway in the MT mechanism as a result of a simultaneous rise in the proportion of tert-butanol reduced to hydroxybutyl (46\% at 1 atm versus $68.5 \%$ at $4 \mathrm{~atm}$ ) and a tripling of the branching ratio from hydroxybutyl to isobutenyl hydroperoxide (9.5\% at $1 \mathrm{~atm}$ versus $34.8 \%$ at $4 \mathrm{~atm}$ ), as shown in Fig. 19(c). The ST mechanism shown in Fig. 14, in contrast, does not contain this pathway from hydroxybutyl, and the branching ratios to iso-butene and propen-2-ol remain quite similar between 1 and 4 atm. 


\subsection{Potential areas for model improvement}

The preceding discussion has highlighted a number of important points regarding the differences between the Sarathy et al. [25] and Merchant et al. [23] models. First, the transport parameters for iso-/sec-/tert-butanol in the Sarathy model - despite describing unreasonably fast fuel diffusion - still cannot account for the disparity between the numerical and experimental data. Furthermore, despite utilizing identical butanol isomer transport parameters, significant differences remain between the Sarathy and Merchant models. These observations suggest that, while the transport model is unquestionably important to the accurate prediction of ignition temperatures, modifications to transport parameters can resolve neither the disparity between the numerical results and the experimental data, nor the differences observed between the Sarathy and Merchant models. This leads to the conclusion that these discrepancies must result from the chemical kinetics. Second, when the skeletal mechanisms from each model are compared, appreciable differences in the fuel breakdown pathways can be observed. For example, as has been discussed at length in previous study [27], the breakdown of $n$-butanol differs substantially between the Sarathy and Merchant models, including significant variations in the predicted branching ratios to both $\gamma$ - and $\delta$-hydroxybutyl (cf. Figs. 11 and 19(a)) as well as the presence of additional pathways involving enols/aldehydes in the Merchant model. With regards to secbutanol, despite describing largely similar chemical pathways and predicting mostly similar branching ratios directly from the parent fuel, path analysis reveals that approximately 5 times more sec-butanol is consumed through butene pathways in the Merchant model relative to the Sarathy model. Moreover, the butene pathways themselves differ substantially. Path analysis reveals that both the branching ratios from the butene isomers as well as the subsequent breakdown pathways are dramatically different. In fact, as a proxy for estimating reactivity, 
additional ignition turning point calculations using butene isomers as a fuel are conducted with both models, showing that 1- and 2-butene ignition occur at $88 \mathrm{~K}$ and $108 \mathrm{~K}$ higher temperatures, respectively, at atmospheric pressure in the Merchant model. Combined with the increased flux through butene pathways, the differing descriptions for butene breakdown likely accounts for the sec-butanol ignition temperature disparity observed between the two models, and likely contributes to differences observed for other isomers as well. Finally, even where substantial agreement exists between the models' ignition temperature predictions - i.e. atmospheric tertbutanol ignition (cf. Fig. 15) - the matching appears to be somewhat serendipitous. As demonstrated for tert-butanol by Figs. 14 and 19(c), even under atmospheric conditions the branching ratios from the hydroxybutyl radical differ dramatically, and the Merchant model even includes an additional ROOH pathway from hydroxybutyl which is absent in the Sarathy model. This ROOH pathway becomes significantly more important at elevated pressures, and likely is a key factor resulting in the growing disparities between the two models as pressure increases.

Taken as a whole, the above observations suggest that despite reasonably matching experimental trends as functions of pressure-weighted strain rate, fuel loading, and pressure, substantial uncertainties remain in the description of combustion chemistry of the butanol isomers. Based upon the above analysis, it is likely that the disparities between the experimental and numerical results cannot be resolved without additional specification of the nature of both butanol and butene breakdown chemistry. With regards to fuel breakdown, Vasu and Sarathy [42] provided minor updates to $n$-butanol unimolecular decomposition reactions based on the shock tube study of Rosado-Reyes and Tsang [43], and additionally increased the rate constant for $\mathrm{H}$-abstraction from formaldehyde, showing slightly improved matching with the data of Stranic et al. [20]. In a recent review of alcohol combustion chemistry, Sarathy et al. [41] also 
pointed out that significant uncertainties remain in the description of $\mathrm{H}$-abstraction reactions from the butanol isomers, particularly by $\mathrm{OH}$ and $\mathrm{HO}_{2}$. Although site-specific $\mathrm{OH}$-abstraction reaction rates developed by McGillen et al. [44] were suggested as a possible avenue of improvement, these reaction rates had yet to be implemented into a combustion model. Additional uncertainties exist with regards to abstraction by $\mathrm{HO}_{2}$, for which no experimental measurements are currently available [41]. Regarding modeling of butene pathways, its submechanism itself is an area of current research. For example, a recent study by Schenk et al. [45] experimentally explored the behavior of the butene isomers in a low-pressure premixed flame configuration and made improvements to an existing hydrocarbon model [46] based upon their results. However, a subsequent study of the ignition of butene isomers in non-premixed counterflow by Zhao et al. [47] discovered significant discrepancies between their experimental data and the model of Schenk et al. [45], and subsequently developed their own butene model which exhibited somewhat improved performance. Taking the above into consideration, it is anticipated that further study of the isomer-specific branching ratios (particularly better understanding of $\mathrm{H}$-abstraction reactions) and the development of comprehensive butene chemistry can help to close the gap between the models, as well as resolve discrepancies between the models and the experimental data. Furthermore, recognizing that the two models do not share the same $\mathrm{C}_{1}-\mathrm{C}_{2}$ sub-mechanism, the foundation fuel chemistry could also play some role in the disparities observed between the Sarathy and Merchant models.

\section{Conclusions}

The present study comprehensively explores the ignition temperature trends of the four butanol isomers as a function of pressure-weighted strain rate $\left(k^{\prime}=200-400 \mathrm{~s}^{-1}\right)$, fuel loading $\left(\mathrm{X}_{\mathrm{f}}=0.05-\right.$ $0.25)$, and pressure $(\mathrm{P}=1-4 \mathrm{~atm})$ in a non-premixed counterflow configuration. These trends are 
compared to numerical results derived from isomer-specific skeletal mechanisms developed from two comprehensive butanol models available in the literature. While these mechanisms largely capture the experimentally-observed trends, they universally over-predict the experimental data to an appreciable extent. Additionally, for both sets of skeletal mechanisms the "ranking" of isomers in terms of predicted ignition temperatures deviates significantly from the experimental results. Whereas the experimental $n$-/iso-/sec-butanol results all lie in close proximity to each other, the Sarathy et al.-based [25] and Merchant et al.-based [23] skeletal mechanisms predict significant separation amongst these isomers. Both ST and MT mechanisms predict largely similar tert-butanol ignition temperatures, although the disparity increases as pressure is raised from atmospheric pressure to 4 atm. Detailed sensitivity and path analyses suggest that the butene isomers may play a significant role in determining the relative levels of reactivity between the butanol isomers, as the relative reactivity of the butanol isomers correlates well with the relative amounts of parent fuel consumed through butene pathways. These trends suggest that the disparities between simulated results from the different base chemical kinetic models may be the result of differing butene chemistry, and that further work is necessary to better define both the branching ratios of reactions leading from the parent fuel to the butene isomers and the subsequent butene chemistry itself.

\section{Acknowledgements}

This material is based upon work supported as part of the Combustion Energy Frontier Research Center, an Energy Frontier Research Center funded by the U.S. Department of Energy, Office of Science, Office of Basic Energy Sciences under Award Number DE-SC0001198. The work at Beihang University was supported by the Project of National Natural Science Foundation of 
China and the Fundamental Research Funds for the Central Universities of China. The authors would additionally like to acknowledge Dr. Kyle Niemeyer at Oregon State University for use of his mechanism reduction package. 


\section{References}

[1] S. Greaves, H. Backman, A.B. Ellison, Transp. Res. Part A Policy Pract. 66 (2014) 226237.

[2] M.M. Thackeray, C. Wolverton, E.D. Isaacs, Energy Environ. Sci. 5 (2012) 7854-7863.

[3] K. Kohse-Höinghaus, P. Oßwald, T.A. Cool, T. Kasper, N. Hansen, F. Qi, C.K.

Westbrook, P.R. Westmoreland, Angew. Chem. Int. Ed. Engl. 49 (2010) 3572-3597.

[4] X. Gu, Z. Huang, S. Wu, Q. Li, Combust. Flame 157 (2010) 2318-2325.

[5] F. Wu, C.K. Law, Combust. Flame 160 (2013) 2744-2756.

[6] S.M. Sarathy, M.J. Thomson, C. Togbé, P. Dagaut, F. Halter, C. Mounaim-Rousselle, Combust. Flame 156 (2009) 852-864.

[7] P.S. Veloo, F.N. Egolfopoulos, Proc. Combust. Inst. 33 (2011) 987-993.

[8] C.M. Mitsingas, D.C. Kyritsis, J. Energy Eng. 140 (2014) A4014006.

[9] J. Hashimoto, K. Tanoue, N. Taide, Y. Nouno, Proc. Combust. Inst. 35 (2014) 973-980.

[10] P.S. Veloo, Y.L. Wang, F.N. Egolfopoulos, C.K. Westbrook, Combust. Flame 157 (2010) 1989-2004.

[11] M.R. Harper, K.M. Van Geem, S.P. Pyl, G.B. Marin, W.H. Green, Combust. Flame 158 (2011) 16-41.

[12] J.K. Lefkowitz, J.S. Heyne, S.H. Won, S. Dooley, H.H. Kim, F.M. Haas, S. Jahangirian, F.L. Dryer, Y. Ju, Combust. Flame 159 (2012) 968-978.

[13] R. Grana, A. Frassoldati, T. Faravelli, U. Niemann, E. Ranzi, R. Seiser, R. Cattolica, K. Seshadri, Combust. Flame 157 (2010) 2137-2154.

[14] P. Oßwald, H. Güldenberg, K. Kohse-Höinghaus, B. Yang, T. Yuan, F. Qi, Combust. Flame 158 (2011) 2-15.

[15] C.S. McEnally, L.D. Pfefferle, C. Taatjes, W. Tsang, H. Hippler, Proc. Combust. Inst. 30 I (2005) 1363-1370. 
[16] P. Dagaut, S.M. Sarathy, M.J. Thomson, Proc. Combust. Inst. 32 (2009) 229-237.

[17] B.W. Weber, C.J. Sung, Energy \& Fuels 27 (2013) 1688-1698.

[18] B.W. Weber, K. Kumar, Y. Zhang, C.J. Sung, Combust. Flame 158 (2011) 809-819.

[19] D.M.A. Karwat, S.W. Wagnon, P.D. Teini, M.S. Wooldridge, J. Phys. Chem. A 115 (2011) 4909-4921.

[20] I. Stranic, D.P. Chase, J.T. Harmon, S. Yang, D.F. Davidson, R.K. Hanson, Combust. Flame 159 (2012) 516-527.

[21] G. Black, H.J. Curran, S. Pichon, J.M. Simmie, V. Zhukov, Combust. Flame 157 (2010) 363-373.

[22] A. Frassoldati, R. Grana, T. Faravelli, E. Ranzi, P. Oßwald, K. Kohse-Höinghaus, Combust. Flame 159 (2012) 2295-2311.

[23] S.S. Merchant, E.F. Zanoelo, R.L. Speth, M.R. Harper, K.M. Van Geem, W.H. Green, Combust. Flame 160 (2013) 1907-1929.

[24] K.M. Van Geem, S.P. Pyl, G.B. Marin, M.R. Harper, W.H. Green, Ind. Eng. Chem. Res. 49 (2010) 10399-10420.

[25] S.M. Sarathy, S. Vranckx, K. Yasunaga, M. Mehl, P. Oßwald, W.K. Metcalfe, C.K. Westbrook, W.J. Pitz, K. Kohse-Höinghaus, R.X. Fernandes, H.J. Curran, Combust. Flame 159 (2012) 2028-2055.

[26] W. Liu, A.P. Kelley, C.K. Law, Proc. Combust. Inst. 33 (2011) 995-1002.

[27] K.B. Brady, X. Hui, C.-J. Sung, K.E. Niemeyer, Combust. Flame (2015) doi: 10.1016/j.combustflame.2015.06.017.

[28] C.L. Yaws, Yaws' Handbook of Thermodynamic and Physical Properties of Chemical Compounds, Knovel, 2003.

[29] K. Seshadri, F.A. Williams, Int. J. Heat Mass Transf. 21 (1978) 251-253. 
[30] C.G. Fotache, T.G. Kreutz, D.L. Zhu, C.K. Law, Combust. Sci. Technol. 109 (1995) 373393.

[31] M.D. Smooke, I.K. Puri, K. Seshadri, Symp. Combust. 21 (1988) 1783-1792.

[32] T.G. Kreutz, M. Nishioka, C.K. Law, Combust. Flame 99 (1994) 758-766.

[33] M. Nishioka, C.K. Law, T. Takeno, Combust. Flame 104 (1996) 328-342.

[34] C.G. Fotache, T.G. Kreutz, C.K. Law, Combust. Flame 108 (1997) 442-470.

[35] C.G. Fotache, H. Wang, C.K. Law, Combust. Flame 117 (1999) 777-794.

[36] K.E. Niemeyer, C.J. Sung, M.P. Raju, Combust. Flame 157 (2010) 1760-1770.

[37] K.E. Niemeyer, C.J. Sung, Combust. Flame 158 (2011) 1439-1443.

[38] K.E. Niemeyer, C.J. Sung, Combust. Flame 161 (2014) 2752-2764.

[39] K.E. Niemeyer, C.J. Sung, Energy \& Fuels 29 (2015) 1172-1185.

[40] CHEMKIN-PRO 15131, Reaction Design: San Diego (2013).

[41] S.M. Sarathy, P. Oßwald, N. Hansen, K. Kohse-Höinghaus, Prog. Energy Combust. Sci. 44 (2014) 40-102.

[42] S.S. Vasu, S.M. Sarathy, Energy \& Fuels 27 (2013) 7072-7080.

[43] C.M. Rosado-Reyes, W. Tsang, J. Phys. Chem. A 116 (2012) 9825-9831.

[44] M.R. McGillen, M. Baasandorj, J.B. Burkholder, J. Phys. Chem. A 117 (2013) 46364656.

[45] M. Schenk, L. Leon, K. Moshammer, P. Oßwald, T. Zeuch, L. Seidel, F. Mauß, K. KohseHöinghaus, Combust. Flame 160 (2013) 487-503.

[46] K. Hoyermann, F. Mauß, T. Zeuch, Phys. Chem. Chem. Phys. 6 (2004) 3824-3835.

[47] P. Zhao, W. Yuan, H. Sun, Y. Li, A.P. Kelley, X. Zheng, C.K. Law, Proc. Combust. Inst. 35 (2014) 309-316. 


\section{Table and Figure Captions}

Table 1: Number of species and reactions contained within the detailed and skeletal mechanisms used in this study.

Figure 1: Ignition turning point validation comparing the results computed from the isomerspecific skeletal mechanisms to those of the detailed Sarathy et al. [25] and Merchant et al. [23] mechanisms. Turning points for (a) $n$-butanol (b) iso-butanol (c) sec-butanol, and (d) tert-butanol are computed at $\mathrm{X}_{\mathrm{f}}=0.15$ for $1 \mathrm{~atm}, k^{\prime}=300 \mathrm{~s}^{-1}$ and $5 \mathrm{~atm}, k^{\prime}=500 \mathrm{~s}^{-1}$. In (b), only the results based on the Sarathy model are shown (cf. Section 2.4.1).

Figure 2: Experimental ignition temperatures for the butanol isomers at $\mathrm{P}=1$ and $3 \mathrm{~atm}, \mathrm{X}_{\mathrm{f}}=0.15$, as a function of pressure-weighted strain rate. Ignition temperature error bars represent the random error of $\pm 5 \mathrm{~K}$, while pressure-weighted strain rate error bars represent the total estimated uncertainty.

Figure 3: Experimental ignition temperatures for the butanol isomers at $\mathrm{P}=1$ and $3 \mathrm{~atm}, k^{\prime}=350 \mathrm{~s}^{-}$ 1 as a function of fuel loading. Ignition temperature error bars represent the random error of $\pm 5 \mathrm{~K}$, while fuel loading error bars represent the total estimated uncertainty.

Figure 4: Experimental ignition temperatures for the butanol isomers at $\mathrm{X}_{\mathrm{f}}=0.15$ and $k^{\prime}=350 \mathrm{~s}^{-1}$ as a function of pressure. Ignition temperature error bars represent the random error of $\pm 5 \mathrm{~K}$, while pressure error bars represent the total estimated uncertainty.

Figure 5: Demonstration of the effect of modifying the Lennard-Jones transport parameters for iso-/sec-/tert-butanol and $\mathrm{C}_{4}$ intermediates related to the parent fuel breakdown in the Sarathy et al. [25] to the matching parameters listed in Merchant et al. [23]. Conditions: $\mathrm{P}=3$ atm and $k^{\prime}=350 \mathrm{~s}^{-1}$. Experimental data are also included for reference.

Figure 6: Comparison between experimental data and numerical predictions using the $\mathrm{SN} / \mathrm{SI} / \mathrm{SS} / \mathrm{ST}$ skeletal mechanisms as a function of pressure for $\mathrm{X}_{\mathrm{f}}=0.15, k^{\prime}=350 \mathrm{~s}^{-1}$.

Figure 7: Normalized (a) reaction rate and (b) binary diffusion sensitivity coefficients for $n$ butanol computed at $\mathrm{P}=1$ and $4 \mathrm{~atm}, k^{\prime}=350 \mathrm{~s}^{-1}, \mathrm{X}_{\mathrm{f}}=0.15$ at the ignition turning point for the $\mathrm{SN}$ skeletal mechanism.

Figure 8: Normalized (a) reaction rate and (b) binary diffusion sensitivity coefficients for isobutanol computed at $\mathrm{P}=1$ and $4 \mathrm{~atm}, k^{\prime}=350 \mathrm{~s}^{-1}, \mathrm{X}_{\mathrm{f}}=0.15$ at the ignition turning point for the SI skeletal mechanism.

Figure 9: Normalized (a) reaction rate and (b) binary diffusion sensitivity coefficients for secbutanol computed at $\mathrm{P}=1$ and $4 \mathrm{~atm}, k^{\prime}=350 \mathrm{~s}^{-1}, \mathrm{X}_{\mathrm{f}}=0.15$ at the ignition turning point for the SS skeletal mechanism.

Figure 10: Normalized (a) reaction rate and (b) binary diffusion sensitivity coefficients for tertbutanol computed at $\mathrm{P}=1$ and 4 atm, $k^{\prime}=350 \mathrm{~s}^{-1}, \mathrm{X}_{\mathrm{f}}=0.15$ at the ignition turning point for the ST skeletal mechanism.

Figure 11: Spatially-integrated path analysis for $n$-butanol at $\mathrm{P}=1$ atm, $k^{\prime}=350 \mathrm{~s}^{-1}, \mathrm{X}_{\mathrm{f}}=0.15$, evaluated at the ignition turning point using the SN skeletal mechanism.

Figure 12: Spatially-integrated path analysis for iso-butanol at $\mathrm{P}=1$ atm, $k^{\prime}=350 \mathrm{~s}^{-1}, \mathrm{X}_{\mathrm{f}}=0.15$, evaluated at the ignition turning point using the SI skeletal mechanism. 
Figure 13: Spatially-integrated path analysis for sec-butanol at $\mathrm{P}=1$ atm, $k^{\prime}=350 \mathrm{~s}^{-1}, \mathrm{X}_{\mathrm{f}}=0.15$, evaluated at the ignition turning point using the SS skeletal mechanism.

Figure 14: Spatially-integrated path analysis for tert-butanol at $\mathrm{P}=1 \mathrm{~atm}, k^{\prime}=350 \mathrm{~s}^{-1}, \mathrm{X}_{\mathrm{f}}=0.15$, evaluated at the ignition turning point using the ST skeletal mechanism. Pathways from the hydroxybutyl radical under 4 atm conditions (in bold) are also included to illustrate differences at elevated pressure, as discussed in Section 3.4.

Figure 15: Comparison between experimental data and numerical predictions using the MN/MS/MT skeletal mechanisms as a function of pressure for $\mathrm{X}_{\mathrm{f}}=0.15, k^{\prime}=350 \mathrm{~s}^{-1}$. Results from the SN/SS/ST skeletal mechanisms are also included for comparison purposes.

Figure 16: Normalized (a) reaction rate and (b) binary diffusion sensitivity coefficients for $n$ butanol computed at $\mathrm{P}=1$ and $4 \mathrm{~atm}, k^{\prime}=350 \mathrm{~s}^{-1}, \mathrm{X}_{\mathrm{f}}=0.15$ at the ignition turning point for the $\mathrm{MN}$ skeletal mechanism.

Figure 17: Normalized (a) reaction rate and (b) binary diffusion sensitivity coefficients for secbutanol computed at $\mathrm{P}=1$ and $4 \mathrm{~atm}, k^{\prime}=350 \mathrm{~s}^{-1}, \mathrm{X}_{\mathrm{f}}=0.15$ at the ignition turning point for the MS skeletal mechanism.

Figure 18: Normalized (a) reaction rate and (b) binary diffusion sensitivity coefficients for tertbutanol computed at $\mathrm{P}=1$ and $4 \mathrm{~atm}, k^{\prime}=350 \mathrm{~s}^{-1}, \mathrm{X}_{\mathrm{f}}=0.15$ at the ignition turning point for the MT skeletal mechanism.

Figure 19: Spatially-integrated path analysis at $\mathrm{P}=1$ atm, $k^{\prime}=350 \mathrm{~s}^{-1}, \mathrm{X}_{\mathrm{f}}=0.15$, evaluated at the ignition turning point (a) for $n$-butanol using the MN skeletal mechanism, (b) for sec-butanol using the MS skeletal mechanism, and (c) for tert-butanol using the MT skeletal mechanism. In (c), some important pathways under 4 atm conditions (in bold) are also included to illustrate differences at elevated pressure, as discussed in Section 3.4. 


\begin{tabular}{|c|c|c|}
\hline Mechanism & Number of Species & Number of Reactions \\
\hline Sarathy et al. (2012) & 426 & 2335 \\
\hline Merchant et al. (2013) & 372 & 8723 \\
\hline SN & 126 & 832 \\
\hline SI & 149 & 953 \\
\hline SS & 126 & 929 \\
\hline ST & 84 & 543 \\
\hline MN & 102 & 1904 \\
\hline MS & 108 & 2197 \\
\hline MT & 117 & 1755 \\
\hline
\end{tabular}

Table 1 

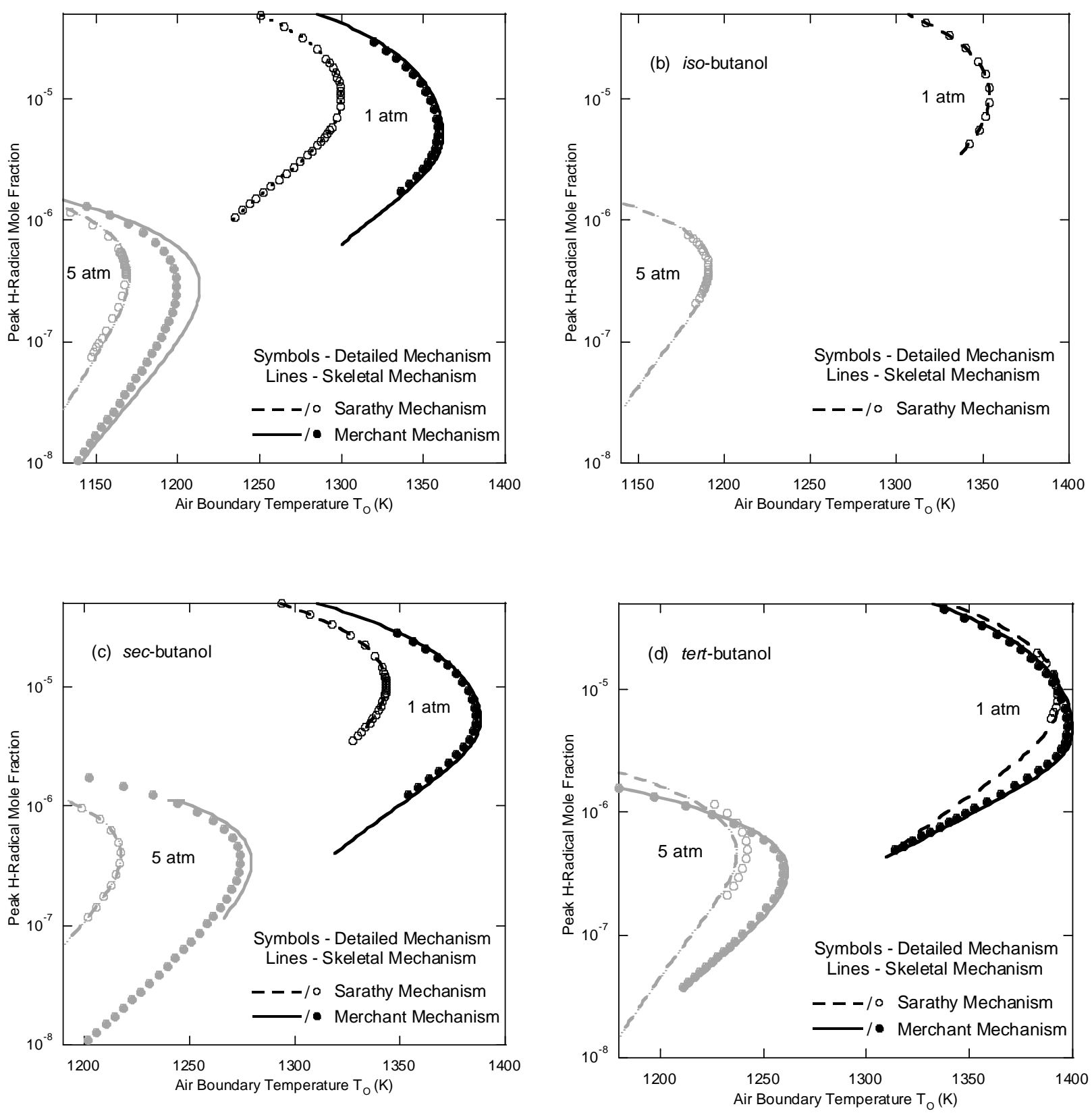

Figure 1 


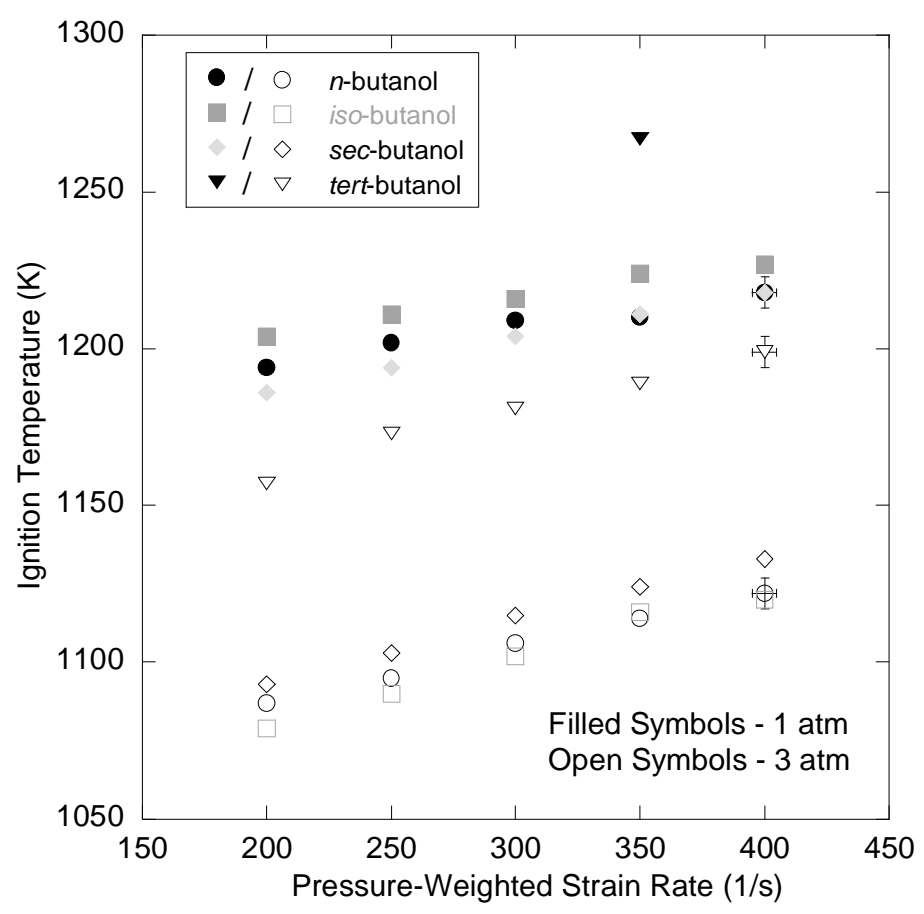

Figure 2

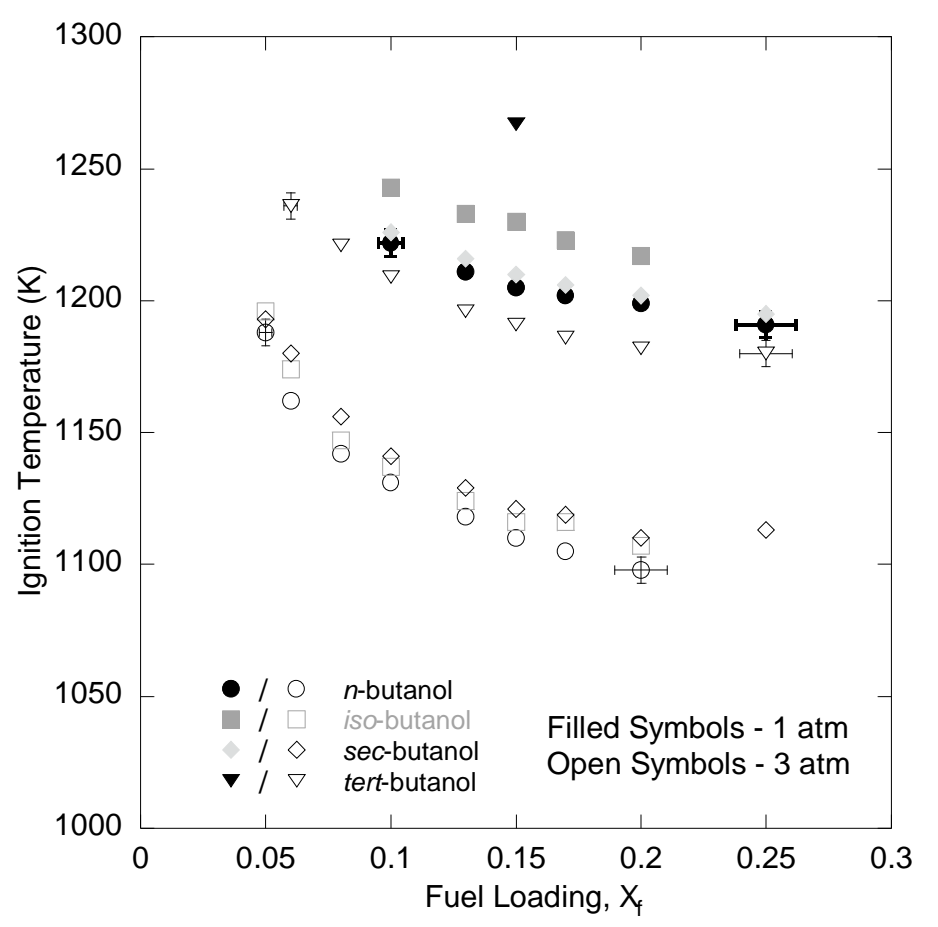

Figure 3 


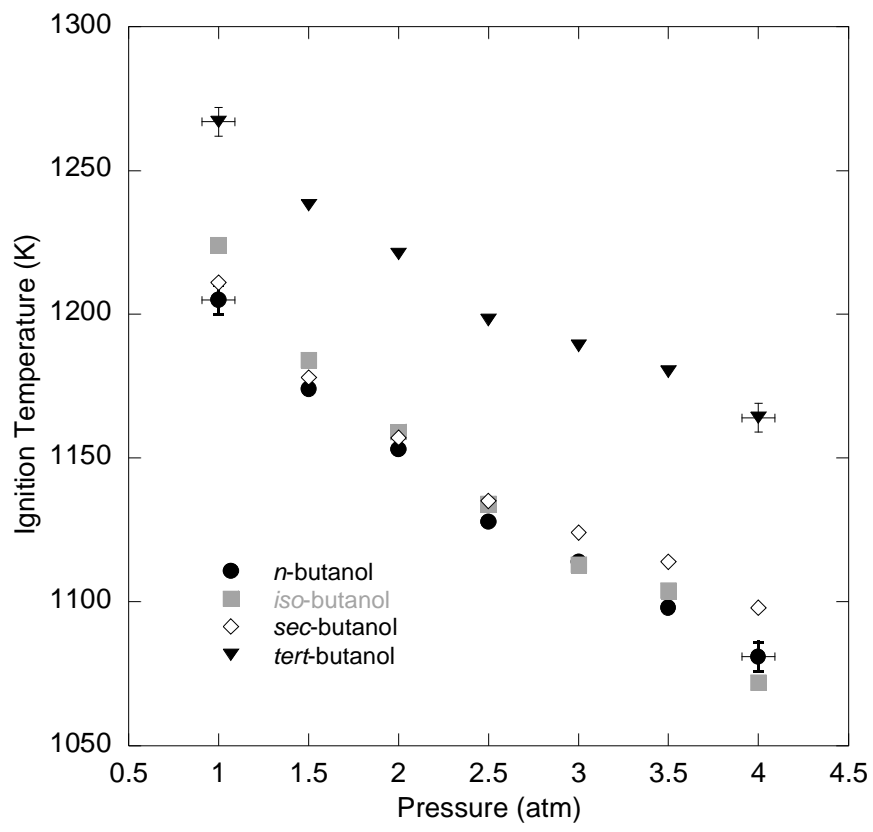

Figure 4

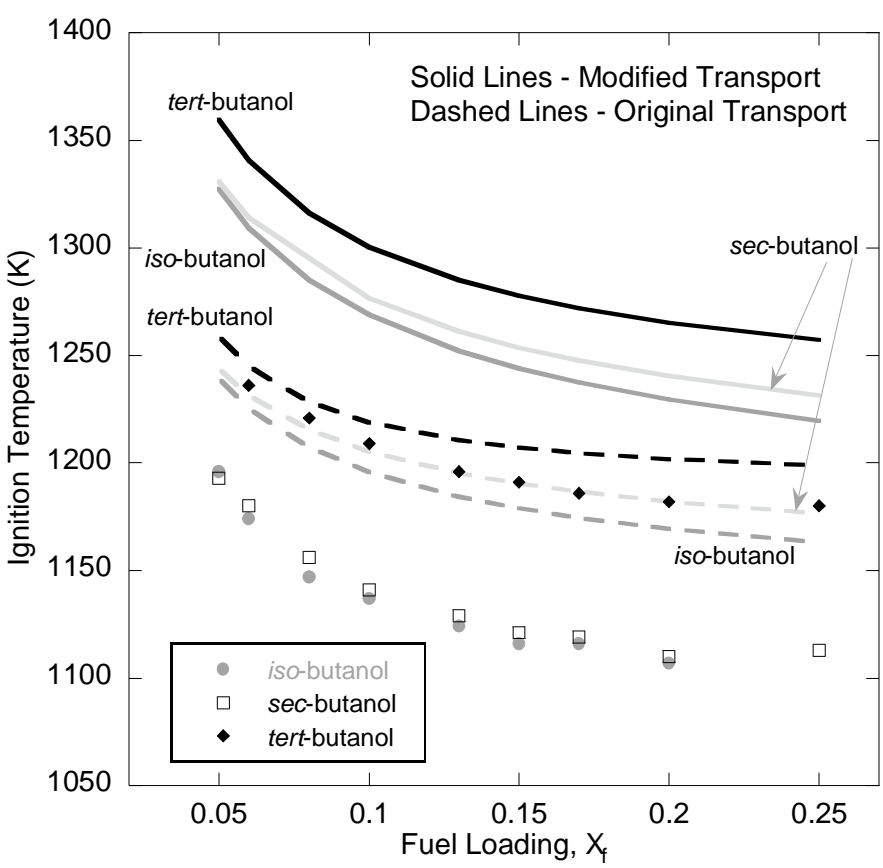

Figure 5 


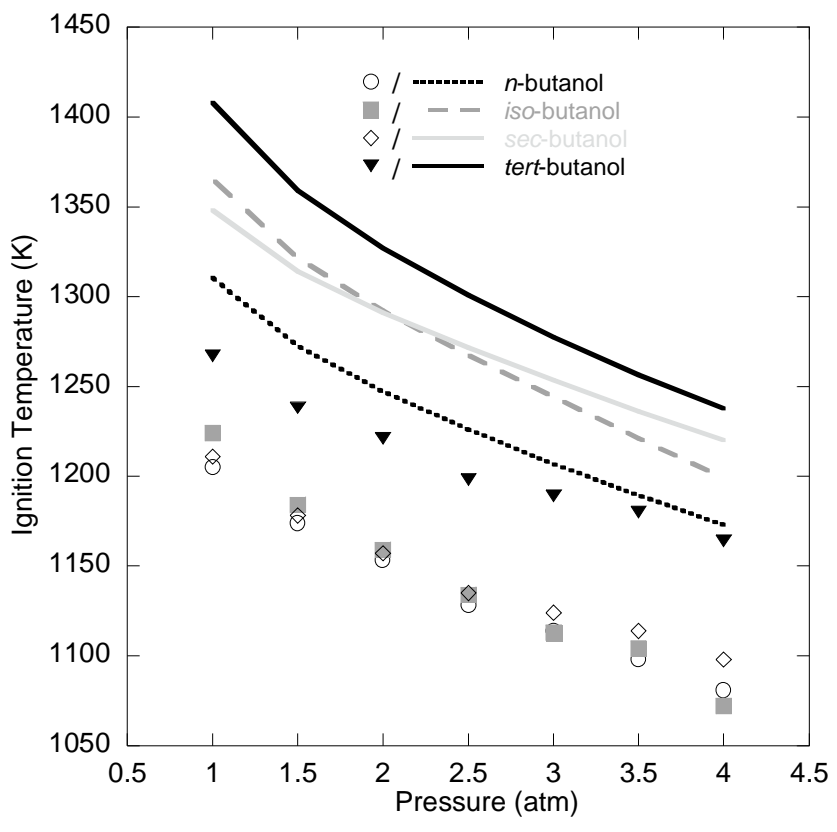

Figure 6 


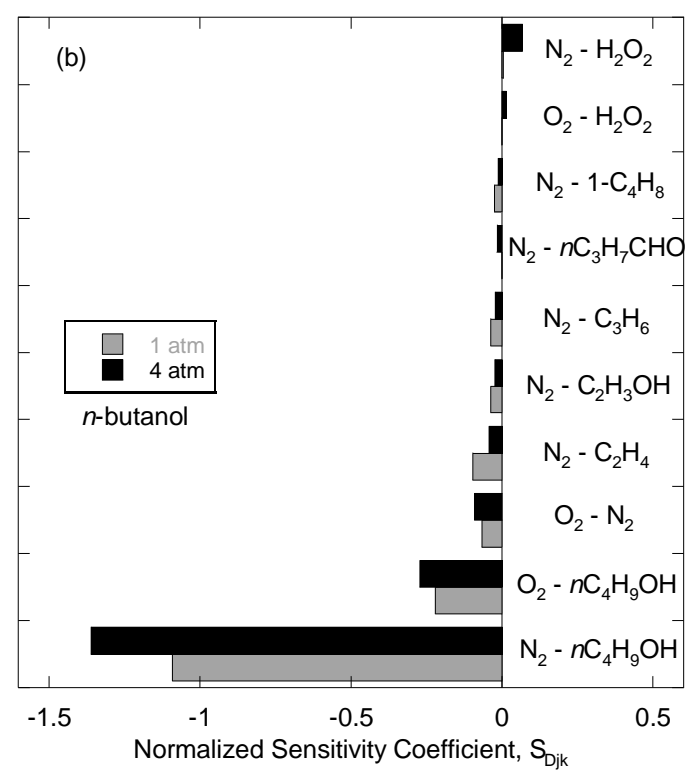

Figure 7
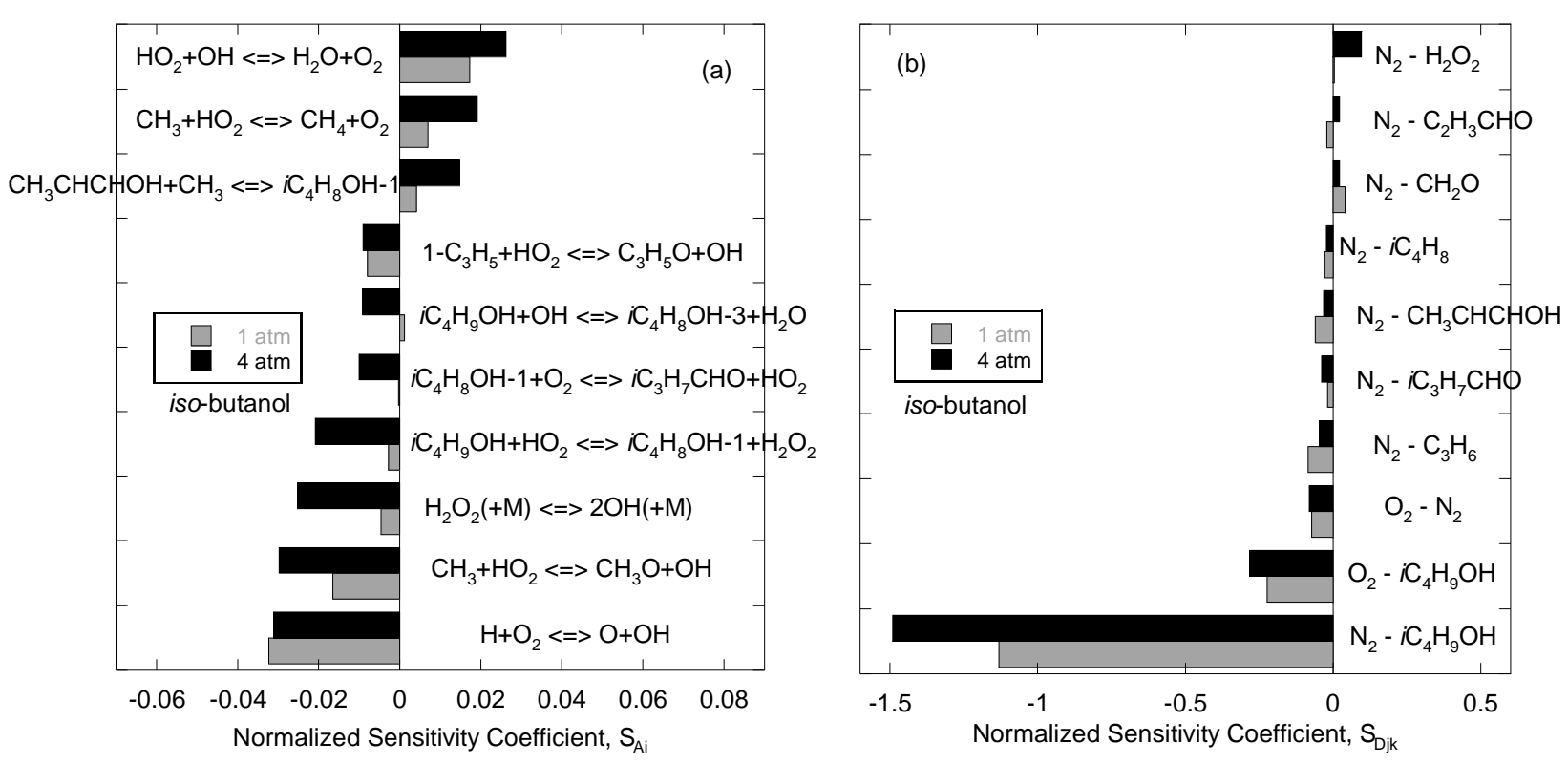

Figure 8 


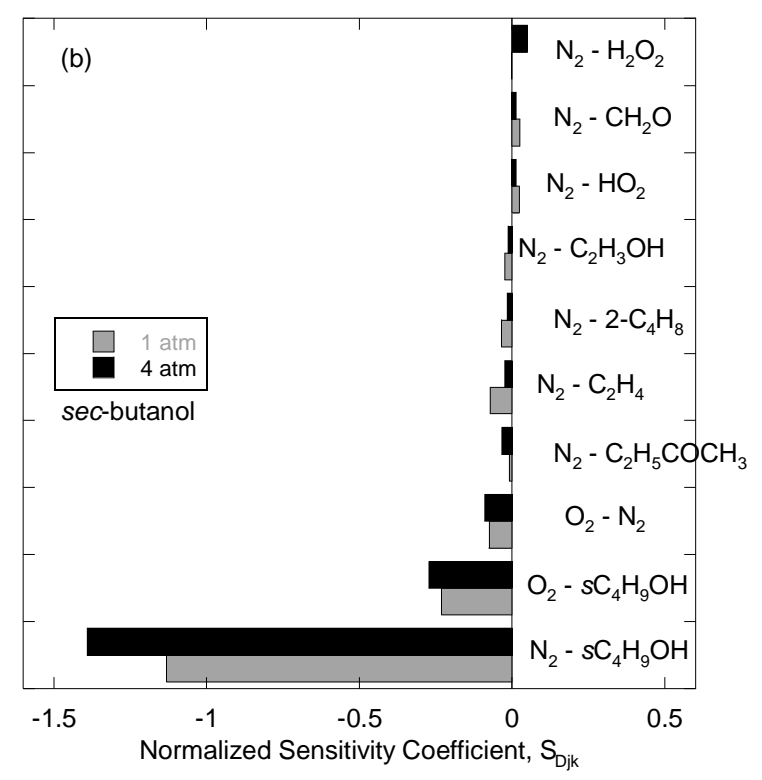

Figure 9
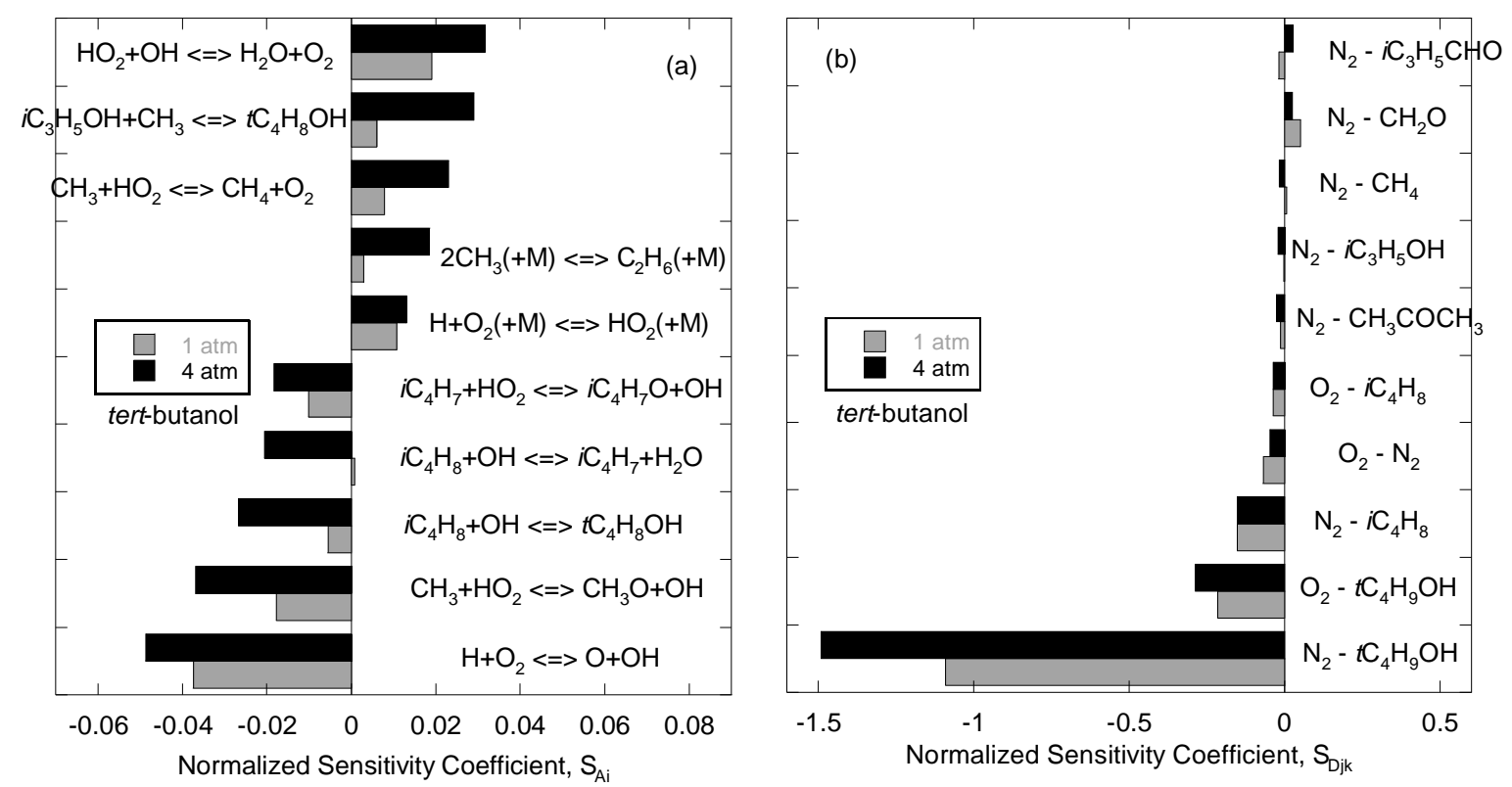

Figure 10 


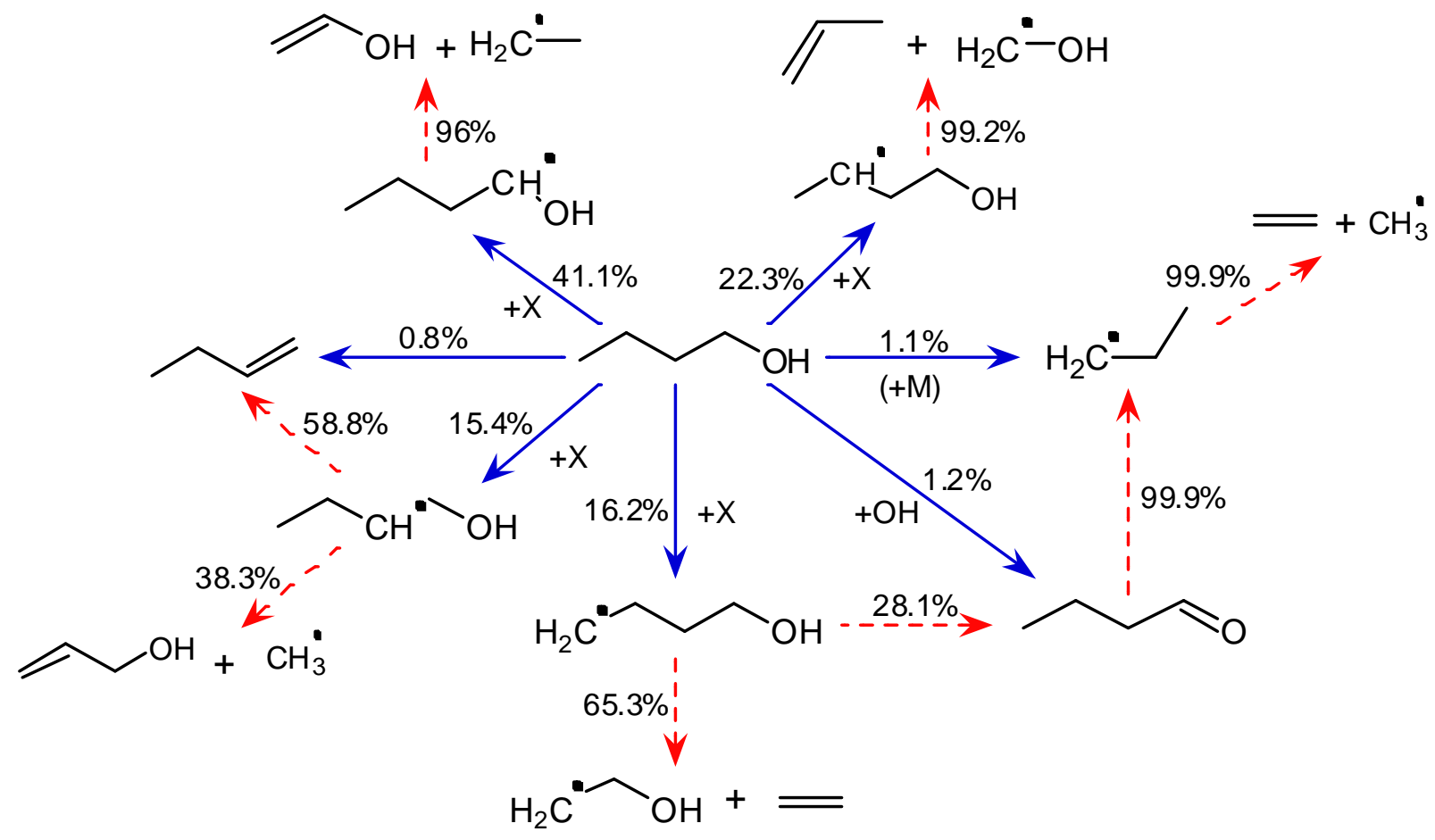

Figure 11

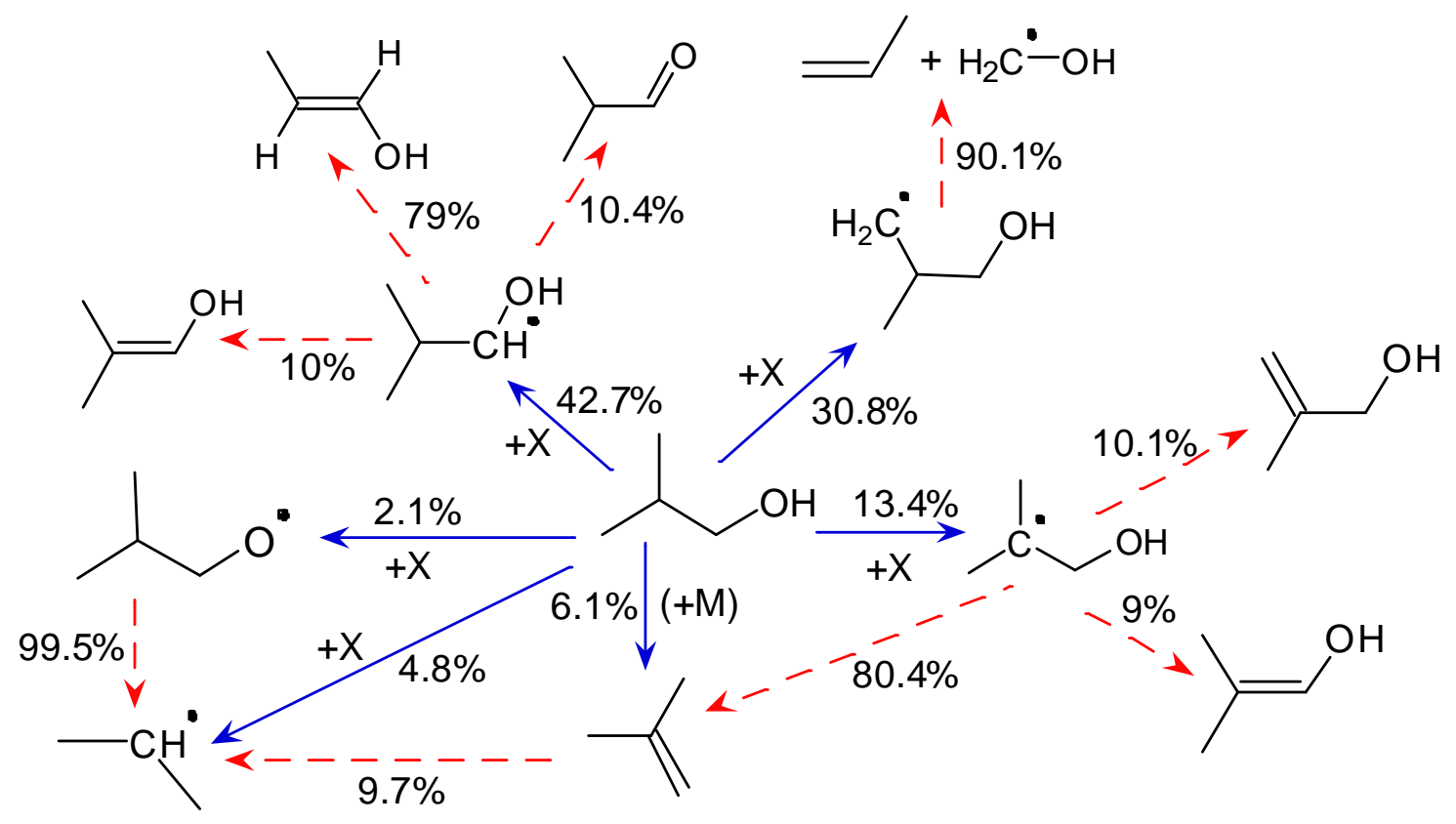

Figure 12 


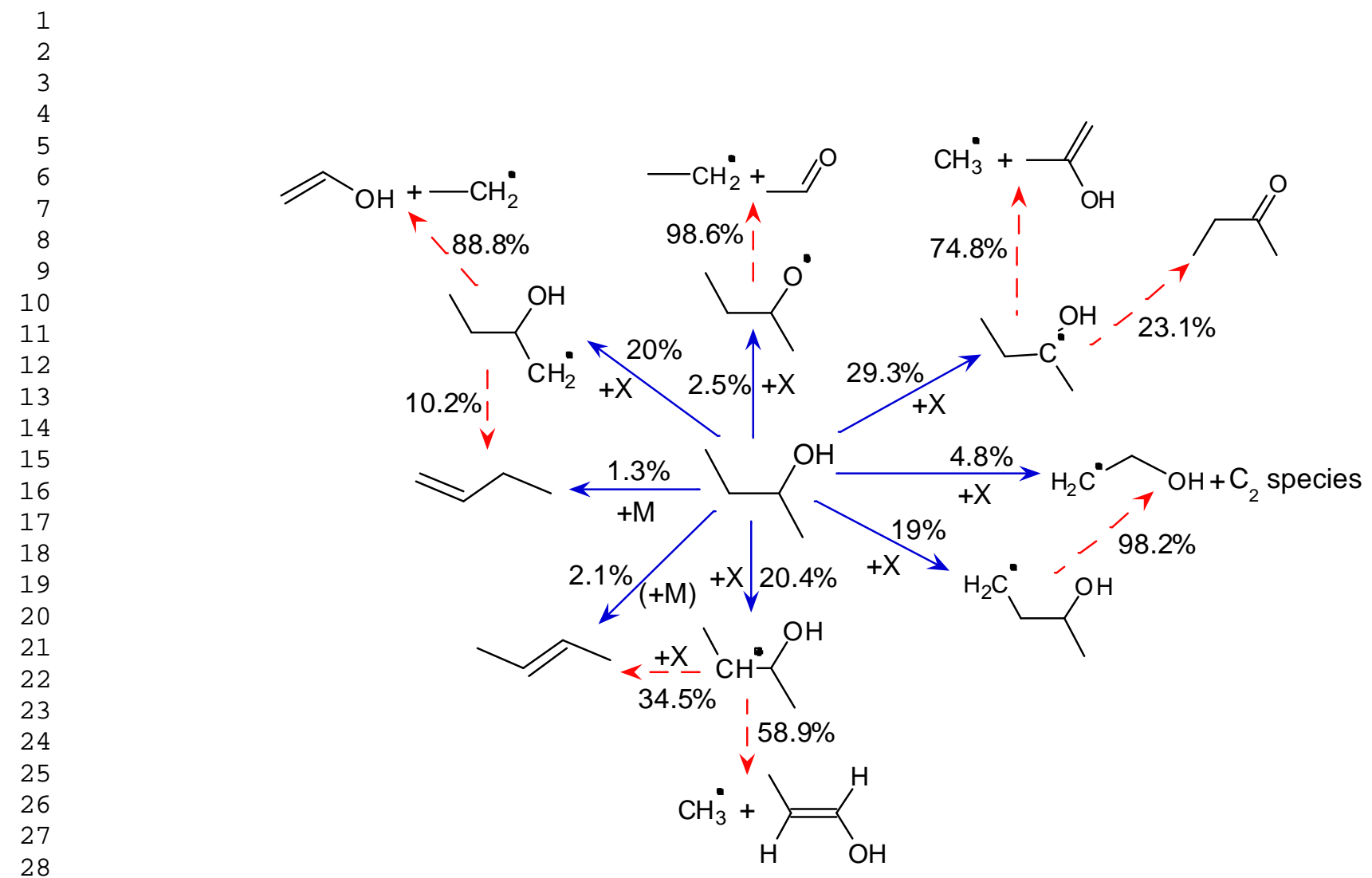

Figure 13

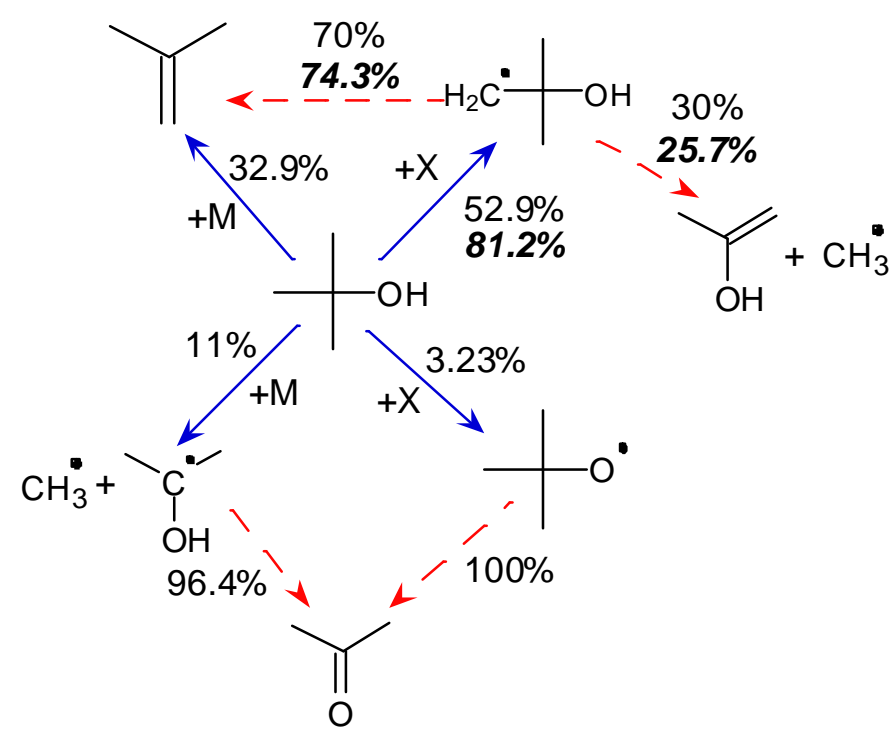

Figure 14 


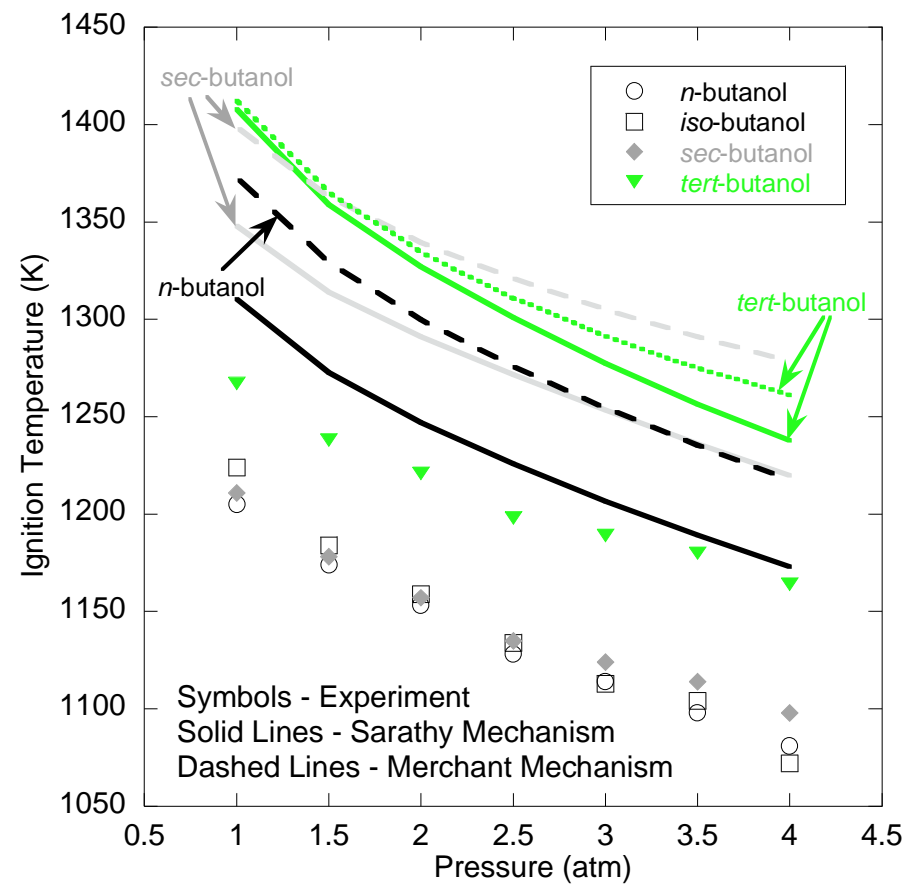

Figure 15
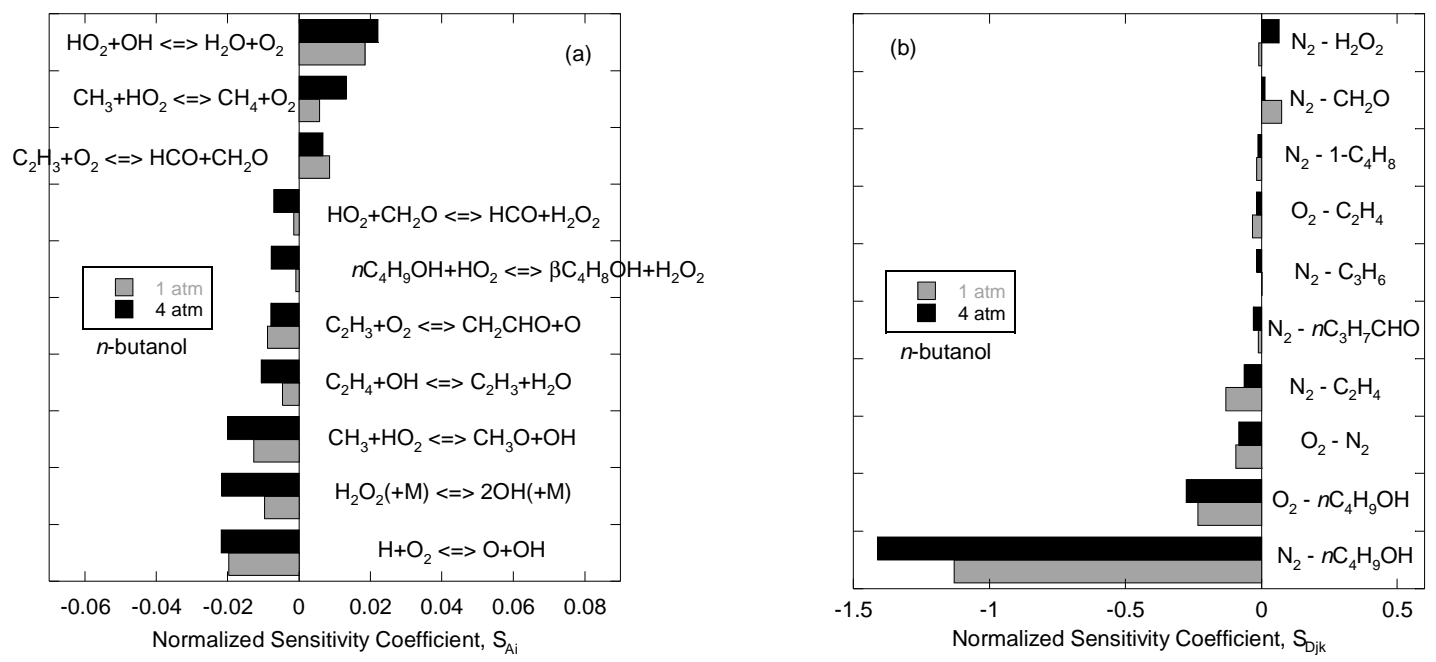

Figure 16 

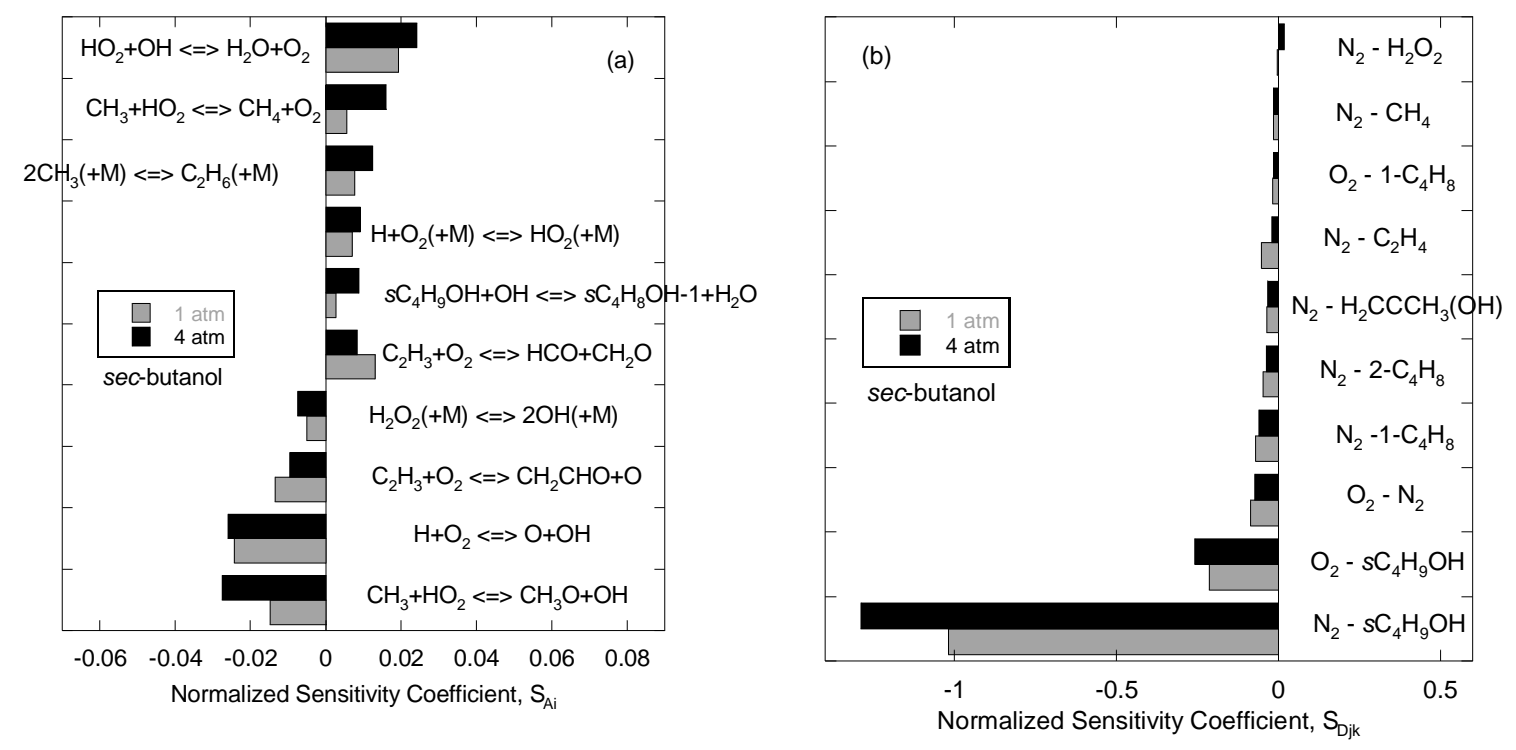

Figure 17
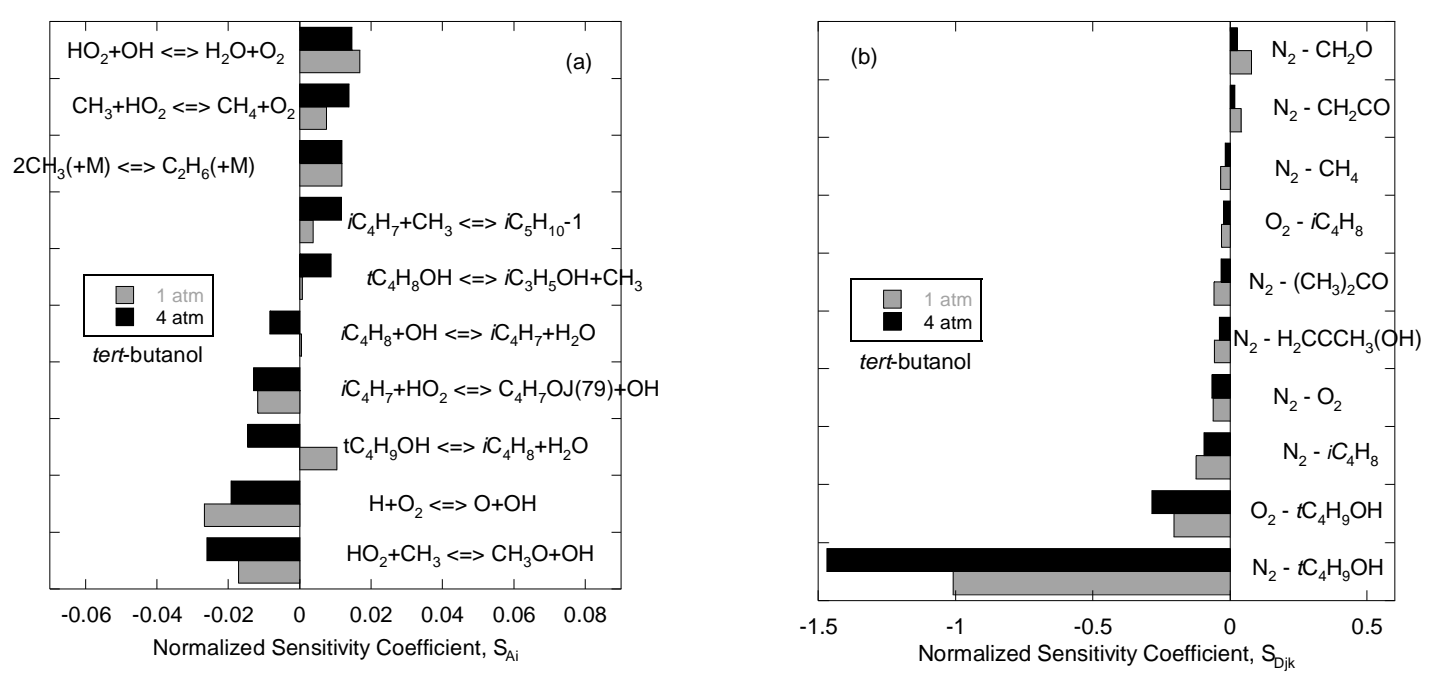

Figure 18 
(a)

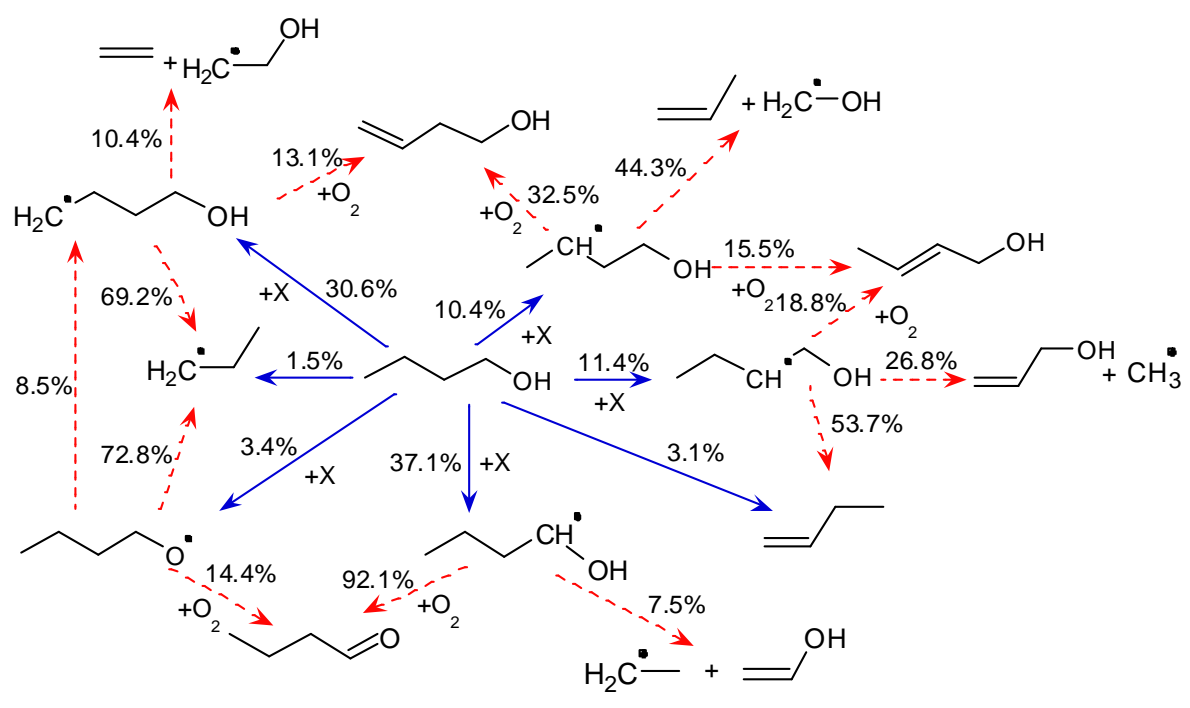

(b)

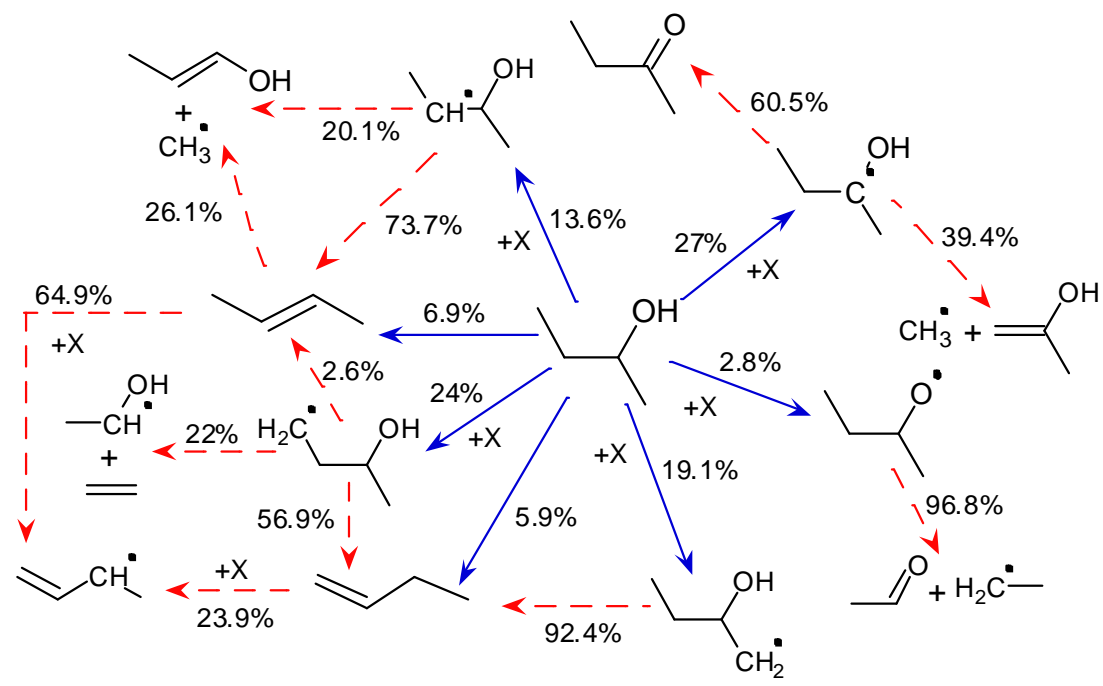

(c)

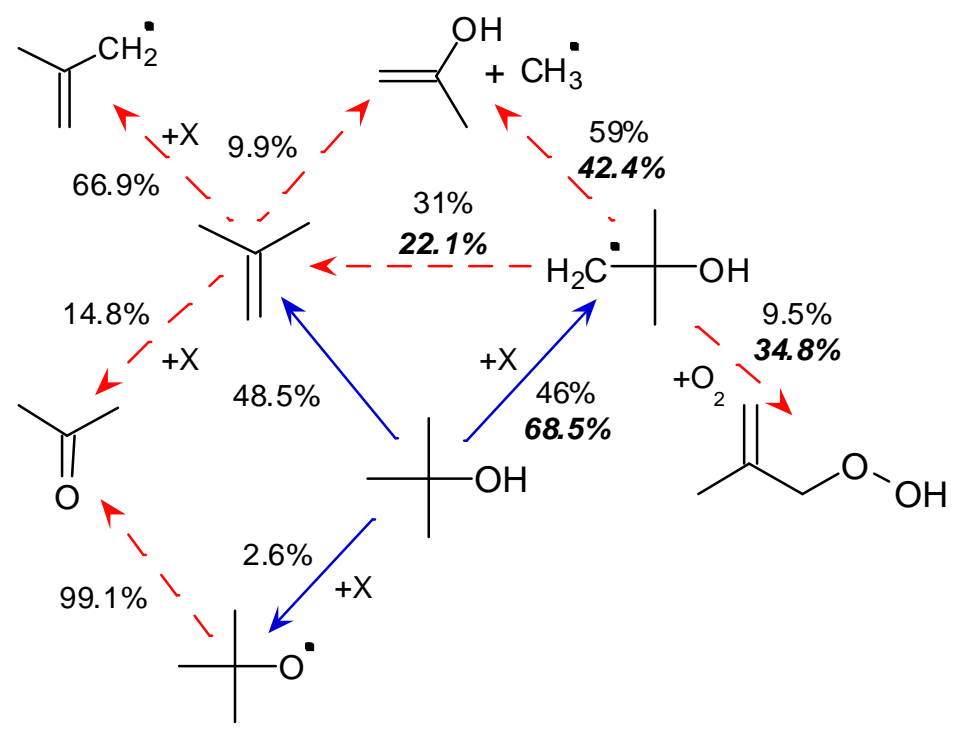

Figure 19 